\title{
Metabarcoding of soil nematodes: the importance of taxonomic coverage and availability of reference sequences in choosing suitable marker(s)
}

\author{
Mohammed Ahmed ${ }^{1,2}$, Matthew Alan Back ${ }^{1}$, Thomas Prior ${ }^{3}$, Gerrit Karssen ${ }^{4}$, Rebecca Lawson ${ }^{3}$, \\ Ian Adams ${ }^{3}$, Melanie Sapp ${ }^{5}$ \\ 1 Harper Adams University, Newport, TF10 8NB, Shropshire, UK. \\ 2 Swedish Museum of Natural History, Department of Zoology, Stockholm, Sweden. \\ 3 Fera, Sand Hutton, YO41 1LZ, North Yorkshire, UK. \\ 4 National Plant Protection Organization Geertjesweg 15, 6706 EA, Wageningen, the Netherlands. \\ 5 Cluster of Excellence on Plant Sciences (CEPLAS), Heinrich Heine University, Population Genetics, 40225 Düsseldorf, Germany. \\ Corresponding author: Mohammed Ahmed (mohammed.ahmed@nrm.se); Melanie Sapp (melanie.sapp@uni-duesseldorf.de)
}

Academic editor: Carmelo Andújar | Received 29 May 2019 | Accepted 24 September 2019 | Published 6 November 2019

\begin{abstract}
For many organisms, there is agreement on the specific genomic region used for developing barcode markers. With nematodes, however, it has been found that the COI region designated for most animals lacks the taxonomic coverage (ability to amplify a diverse group of taxa) required of a metabarcoding marker. For that reason, studies on metabarcoding of nematodes thus far have utilized primarily regions within the highly conserved $18 \mathrm{~S}$ ribosomal DNA. Two popular markers within this region are the ones flanked by the primer pairs NF1-18Sr2b and SSUF04-SSUR22. The NF1-18Sr2b primer pair, especially, has been critiqued as not being specific enough for nematodes leading to suggestions for other candidate markers while the SSUF04-SSUR22 region has hardly been tested on soil nematodes. The current study aimed to evaluate these two markers against other alternative ones within the 28S rDNA and the COI region for their suitability for nematode metabarcoding. The results showed that the NF1-18Sr2b marker could offer wide coverage and good resolution for characterizing soil nematodes. Sufficient availability of reference sequences for this region was found to be a significant factor that resulted in this marker outperforming the other markers, particularly the 18S-based SSUFO4-SSUR22 marker. None of the other tested regions compared with this marker in terms of the proportion of the taxa recovered. The COI-based marker had the lowest number of taxa recovered, and this was due to the poor performance of its primers and the insufficient number of reference sequences in public databases. In summary, this study highlights how dependent the success of metabarcoding is on the availability of a good reference sequence collection for the marker of choice as well as its taxonomic coverage.
\end{abstract}

\section{Key Words}

barcoding, taxonomy, DNA marker, nuclear, mitochondrial, reference database, primer

\section{Introduction}

Fundamental to any DNA sequence-based identification method is the choice of barcode marker(s) (Wilkinson et al. 2017). The chosen marker has to meet most of the criteria outlined by Floyd et al. (2002). Essentially, the targeted region must be a mosaic of conserved and variable motifs. Conservation of the region, particularly the flanks, is necessary for designing universal primers.
Within the region, conservation may also be necessary to ensure similarity between individuals of the same species. Likewise, a certain degree of variability within the sequence is required for distinguishing between species. Moreover, for the query sequence to be classified, reference sequences of this marker need to be available. Depending on the organism being studied, such a mark- 
er may occur within the nuclear, mitochondrial or plastid DNA.

Within the mitochondrial DNA, the cytochrome $c$ oxidase subunit I (COI) protein coding gene has been the most widely used region, especially for DNA-barcoding of animals. Most studies involving insects and birds have utilized a region of this gene (Hebert et al. 2003, 2004, 2016, Ramage et al. 2017). The region has been shown to be unique among at least $95 \%$ of studied species of diverse groups of organisms including birds, insects, fish etc. (Hajibabaei et al. 2007) and is thus capable of delineating most species of these groups. The use of this region has also been facilitated largely by the enormity of the number of its sequences within the Barcode of Life Data Systems database (BOLD) (Ratnasingham and Hebert 2007) with the collection numbering over 7.5 million validated sequences in mid-2019.

Despite its success as a barcode marker for most animals, attempts to utilize COI for some nematodes have not been successful for a number of reasons (Creer et al. 2010). One reason is the extremely high mutation rate of the mtDNA in nematodes compared to other taxa (Blouin et al. 1995, Anderson et al. 1998), which hinders the design of universal primers. The hybridization sites for the most widely used primer set LCO1490 - HCO2198 (Folmer et al. 1994) are poorly conserved across the nematode phylum (Blouin et al. 1998) which is likely to result in poor amplification and consequently poor recovery of taxa in bulk community analysis. The primers amplify approximately $710 \mathrm{bp}$ of the COI gene, which typically gives 651 bp of readable sequences (Folmer et al. 1994).

Besides being used for discriminating species of certain genera of nematodes (Janssen et al. 2016), most mtDNA-based markers have been largely overlooked in metabarcoding due to their limited taxonomic coverage of the nematode phylum. A similar argument was put forward by Deagle et al. (2014) who demonstrated how narrow the taxonomic coverage of some of the markers situated within the mitochondrial genome is. Furthermore, a significant proportion of the many COI nematode sequences in the BOLD database belong to parasites of vertebrates, insects and plants, making this region not particularly useful for free-living nematode community analysis.

The most widely used markers for metabarcoding to date have been ones associated with the nuclear ribosomal RNA gene repeats (rDNA)(Porazinska et al. 2009, 2010a, 2010b, 2012, Creer et al. 2010, Fonseca et al. 2010, Bik et al. 2012, Holovachov et al. 2017). In eukaryotes, rDNA units are known to occur in copies of up to several hundred tandem repeats per genome (Hillis and Dixon 1991). In Caenorhabditis elegans, the array contains approximately 55 copies of the complete unit (Ellis et al. 1986). And within the nematode phylum, copy numbers range from 50 to 100 (Floyd et al. 2002). According to Creer et al. (2010), 18S and 28S subunits of this gene offer an excellent choice of barcode regions due to their multiple copies and the concerted evolution events they have been reported to undergo (Elder and Turner 1995). This helps maintain fairly identical copies within each species.

The 18S rDNA-based markers like all markers mentioned here have certain limitations. Aside from the fact that some $18 \mathrm{~S}$ rDNA markers lack the resolution to distinguish certain species of nematodes, the primers used for amplification are often not specific. Using the primer pair described by Porazinska et al. (2009) on DNA extracted directly from soil, Peham et al. (2017) showed that only $2.5 \%$ of sequenced reads belonged to nematodes. To make this specific marker suitable for environmental DNA, Sapkota and Nicolaisen (2015) proposed the use of a semi-nested amplification approach they showed could increase the percentage of nematode reads from just $3 \%$ to $64 \%$. This lack of primer specificity within this region may remain a minor issue as long as nematodes are isolated from the soil prior to DNA extraction. Given that current direct soil extraction kits can only handle a very small fraction of the recommended soil volume for nematode extraction (250 $\mathrm{ml}$ ) (Peham et al. 2017), it is safe to say that the traditional extraction methods will continue to be widely used until the direct DNA extraction kits are improved. Peham et al. (2017) also made a case for the internal transcribed spacers (ITS) region to be considered as a barcode candidate given the large collection of sequence reference libraries of this marker available in public databases (Peham et al. 2017). However, as stated by Floyd et al. (2002), attributes of the ITS region such as its high variability even within species and showing extreme length variation between diverse nematode taxa make it a difficult marker to use. Within some species of Cephalenchus, such length variation can be as high as $29 \mathrm{bp}$ in the ITS1 region (Yarza et al. 2008)

Two regions within the $18 \mathrm{~S}$ rDNA are commonly used in metabarcoding studies involving nematodes. The first is a region amplified using the primer sets NF1-18Sr2b as used by Porazinska et al. (2009), which will from hereon be called NF1-18Sr2b marker. The second one is amplified with primers SSU04F-SSUR22 (Blaxter et al. 1998) and has been used in a number of previous studies on metabarcoding of marine nematodes (Porazinska et al. 2009, 2010b, Creer et al. 2010, Fonseca et al. 2010, 2014, Bik et al. 2012, Holovachov et al. 2017). This second marker, which will hereon be referred to as SSUF04-SSUR22, is located very close to the $5^{\prime}$ end of the $18 \mathrm{~S}$ rDNA. Generally, NF1-18Sr2b has been the preferred choice for soil nematodes and the SSUF04-SSUR22 for marine nematodes (Creer et al. 2010, Porazinska et al. 2010b, 2010a, Fonseca et al. 2014, Holovachov et al. 2017). Another rDNA-based marker located within the D3 expansion segment of the 28S rDNA has been previously tested on mock communities of nematodes (Porazinska et al. 2009). This region is amplified using the primer set D3Af-D3Br (Nunn 1992). Porazinska et al. (2009) showed that it was able to detect $\sim 90 \%$ of the sampled species, and when combined with NF1-18Sr2b, enhanced the recovery of the sampled taxa to $95 \%$. The COI-region amplified using the JB3-JB5GED (Derycke et al. 2010) primer pairs is also included in this comparison. It is clear that the $\mathrm{COI}$ region 
has the limitation of lacking truly universal PCR primers (Deagle et al. 2014). Nonetheless, it has been included so that its performance relative to other markers, that may themselves have limitations, can be compared. The aim of this study was to compare the overall suitability of these markers for metabarcoding of soil nematodes based on (i) success with merging of paired reads, (ii) proportion of reads belonging to identified nematode and non-nematode OTUs, (iii) availability and coverage of markers within reference libraries, (iv) accuracy of taxonomy assignment and (v) abundance estimate and reproducibility of relative read frequencies of the taxa across replicates.

\section{Materials and methods}

\section{Sample extraction and microscopy}

The taxa represented in the mock community were obtained either from pure cultures or soil samples from within the grounds of Fera Science Ltd. in Sand Hutton, York, UK (54.015514, -0.970281). For Meloidogyne hapla and Globodera rostochiensis, pure cultures of second stage juveniles were used. For Steinernema carpocapsae dauer larvae were used. For cultures of Trichodorus primitivus, Ditylenchus dipsaci and Laimaphelenchus penar$d i$, adult females and/or males were used. Adult stages appropriate for reliable identifications were used for all taxa that were not kept in culture but obtained from soil samples. For most of the taxa, the Whitehead tray method (Whitehead and Hemming 1965) was used for extraction. Soil samples weighing $300 \mathrm{~g}$ were used in each extraction and allowed to stand for $48 \mathrm{hrs}-72 \mathrm{hrs}$. For the extraction of stubby root nematodes (Trichodoridae) the two-flask method (Seinhorst 1955) was also used on 300 g soil samples. Following extraction, the nematodes were identified at low power (40× magnification) using a Leica M50 stereomicroscope (Leica microsystems Wetzlar, Germany). Three to five individuals of the same order/ family were then temporarily mounted on to a slide in a drop of water, covered with a cover slip and sealed with nail varnish. The specimens were then identified to the genus or species level under a high-power (x1000 magnification) compound microscope (Zeiss Axio Imager 2, ZEISS, Germany) equipped with differential interference contrast (DIC). This was done only for the taxa that were not kept in culture or already known.

\section{Mock community}

Three replicates of artificial assemblages of nematodes were used as mock communities. For each replicate 23 different genera of known abundances were placed in Eppendorf tubes containing $20 \mu \mathrm{l}$ of molecular grade water (MGW). The mock communities were assembled to consist of taxa spanning as much diversity across the phylum as possible. In total, 19 different families belonging to six orders within the phylum Nematoda were represented (Table 1).
Table 1. Nematode taxa included in the mock community, their families and abundances. Classifications are based on De Ley and Blaxter (2002). GenBank Accession numbers correspond to LSU (SSU for Plectus sp. only) sequences of the single specimens sequenced using the Sanger method.

\begin{tabular}{|c|c|c|c|}
\hline Family & Species & $\begin{array}{c}\text { GenBank } \\
\text { Access. No }\end{array}$ & Abundance \\
\hline Alaimidae & Alaimus sp. & MG994936 & 2 \\
\hline Trichodoridae & Trichodorus primitivus & MG994943 & 1 \\
\hline Tripylidae & Tripyla glomerans & MG994928 & 2 \\
\hline Longidoridae & $\begin{array}{l}\text { Longidorus } \\
\text { caespiticola }\end{array}$ & MG994935 & 1 \\
\hline Longidoridae & $\begin{array}{l}\text { Xiphinema } \\
\text { diversicaudatum }\end{array}$ & MG994934 & 1 \\
\hline Aporcelaimidae & Aporcelaimellus sp. & MG994940 & 1 \\
\hline Mononchidae & Prionchulus punctatus & MG994945 & 2 \\
\hline Anatonchidae & Anatonchus tridentatus & MG994941 & 1 \\
\hline Plectidae & Anaplectus sp. & MG994930 & 1 \\
\hline Plectidae & Plectus sp. & MG993558 & 2 \\
\hline Neodiplogasteridae & Pristionchus sp. & MG994929 & 3 \\
\hline Anguinidae & Ditylenchus dipsaci & MG994937 & 3 \\
\hline Rhabditidae & Rhabditis sp. & MG994944 & 3 \\
\hline Steinernematidae & $\begin{array}{l}\text { Steinernema } \\
\text { carpocapsae }\end{array}$ & MG994932 & 12 \\
\hline Cephalobidae & Acrobeles sp. & MG994931 & 1 \\
\hline Cephalobidae & Acrobeloides sp. & Failed & 2 \\
\hline Tylenchidae & Tylenchus sp. & Too short & 3 \\
\hline Aphelenchoididae & $\begin{array}{l}\text { Laimaphelenchus } \\
\text { penardi }\end{array}$ & $\begin{array}{c}\text { Not } \\
\text { sequenced }\end{array}$ & 8 \\
\hline Aphelenchoididae & Aphelenchoides sp. & MG994938 & 2 \\
\hline Hemicycliophoridae & Hemicycliophora sp. & MG994927 & 3 \\
\hline Criconematidae & Criconema sp. & Failed & 1 \\
\hline Heteroderidae & $\begin{array}{l}\text { Globodera } \\
\text { rostochiensis }\end{array}$ & MG994942 & 10 \\
\hline Meloidogynidae & Meloidogyne hapla & $\begin{array}{c}\text { Not } \\
\text { sequenced }\end{array}$ & 7 \\
\hline
\end{tabular}

\section{DNA extraction}

Extractions of DNA from the mock community replicates and the single specimens were performed using the Qiagen DNeasy Blood and Tissue Kit (Qiagen, Manchester, UK). All samples (single-specimen samples and the three mock community replicates) were placed in $1.5 \mathrm{ml} \mathrm{mi-}$ crocentrifuge tubes containing $20 \mu \mathrm{l}$ of MGW. The tubes were topped up to $180 \mu \mathrm{l}$ by adding $160 \mu \mathrm{l}$ of Qiagen ATL buffer, followed by $20 \mu \mathrm{l}$ proteinase $\mathrm{K}$ before being incubated overnight at $56{ }^{\circ} \mathrm{C}$. The lysed samples were further processed to obtain pure DNA according to the manufacturer's instructions for genomic DNA extraction.

Molecular identification of single specimens using Sanger Sequencing

Sequences of single specimens for 21 of the taxa represented in the mock community were analyzed separately using the Sanger sequencing method for confirmation of their identities based on three distinct genomic regions. Each specimen was picked into a separate Eppendorf tube and sequences of three different regions were analyzed. 
These regions were a nearly complete $18 \mathrm{~S}$ rDNA region, the D2-D3 segment of the 28S rDNA region and the COI region. Meloidogyne hapla and Laimaphelenchus sp. had previously been studied and identified and so did not require molecular confirmation.

Amplification of single specimen samples. For the $18 \mathrm{~S}$ rDNA, an approximately 1800 bp long region was amplified as two overlapping fragments using two primer sets 988F-1912R and 1813F-2646R for the first and second fragments respectively (Holterman et al. 2006).

The polymerase chain reaction (PCR) amplification of both fragments of the $18 \mathrm{~S}$ rDNA region was carried out in $25 \mu 1$ reactions containing, $5 \mu \mathrm{l}$ template DNA, $12.5 \mu \mathrm{l}$ of $2 \times \mathrm{BIO}-\mathrm{X}-\mathrm{ACT}$ short mix (Bioline reagents Limited, London), $0.25 \mu \mathrm{M}$ of each primer namely 988F (5'-CTCAAAGATTAAGCCATGC-3') and 1912R (5'-TTTACGGTCAGAACTAGGG-3') for the first fragment; 1813F (5'-CTGCGTGAGAGGTGAAAT-3') and 2646R (5'-GCTACCT GTTACGACTTTT-3') for the second fragment, and $6.3 \mu \mathrm{MGW}$. The PCR conditions were $5 \mathrm{~min}$ at $95^{\circ} \mathrm{C} ; 5$ cycles of $\left(94{ }^{\circ} \mathrm{C}\right.$ for $30 \mathrm{sec}, 45$ ${ }^{\circ} \mathrm{C}$ for $30 \mathrm{~s}$ and at $72{ }^{\circ} \mathrm{C}$ for $\left.30 \mathrm{sec}\right) ; 35$ cycles of $\left(94^{\circ} \mathrm{C}\right.$ for $30 \mathrm{sec}, 54^{\circ} \mathrm{C}$ for $30 \mathrm{~s}$ and $72{ }^{\circ} \mathrm{C}$ for $30 \mathrm{~s}$ ); and a final extension for $5 \mathrm{~min}$ at $72^{\circ} \mathrm{C}$.

The D2-D3 segment of the 28S rDNA region was amplified using the primers D2Af and D3Br (Nunn 1992). The $25 \mu 1$ reactions were made of up of $5 \mu 1$ template DNA, $12.5 \mu \mathrm{l}$ of $2 \times$ BIO-X-ACT short mix, $0.25 \mu \mathrm{M}$ of each of primers D2Af (5'-ACAAGTACCGTGAGGGAAAGTTG-3') and D3Br (5'-TCGGAAGGAACCAGCTACTA-3') and $6.3 \mu \mathrm{l} \mathrm{MGW.} \mathrm{The} \mathrm{PCR} \mathrm{conditions}$ were as follows: 4 min at $94{ }^{\circ} \mathrm{C} ; 35$ cycles of $\left(94{ }^{\circ} \mathrm{C}\right.$ for $60 \mathrm{~s}, 54{ }^{\circ} \mathrm{C}$ for $90 \mathrm{~s}$ and $72{ }^{\circ} \mathrm{C}$ for $2 \mathrm{~min}$ ); final extension for $10 \mathrm{~min}$ at $72{ }^{\circ} \mathrm{C}$.

The 400 bp region of the COI gene was amplified using the JB3-JB5GED primers (Bowles et al. 1992, Derycke et al. 2010). Amplification was carried out in $25 \mu 1$ reactions containing the same components as with the other markers. The cycle programme consisted of an initial denaturation at $95^{\circ} \mathrm{C}$ for $5 \mathrm{~min}$, followed by 40 cycles of denaturation at $95^{\circ} \mathrm{C}$ for $1 \mathrm{~min}$, primer annealing at 41 ${ }^{\circ} \mathrm{C}$ for $30 \mathrm{~s}$ and extension at $72{ }^{\circ} \mathrm{C}$ for $2 \mathrm{~min}$; then a final extension at $72{ }^{\circ} \mathrm{C}$ for $10 \mathrm{~min}$.
The PCR amplicons were purified using the QIAquick PCR Purification Kit (Qiagen) before being sent to Eurofins Genomics (https://eurofinsgenomics.eu) for sequencing using the same primers used for the PCR. The sequences obtained for single specimens are available from GenBank (Benson et al. 2018) under the accession numbers MG993556-MG993565 and MG994920-MG994946.

Analysis of Sanger Sequence data from single specimen samples. Sequences were received as both ABI and SEQ files. Both sequence file formats were visualized using BioEdit Sequence Alignment Editor (Hall 1999). The ABI files provided the chromatographs for the base calls. Based on this, each sequence was visually edited to high quality by removing areas of ambiguous base calling inside BioEdit. Some of the edited forward and reverse reads could not be merged due to a lack of overlap between the two pairs after editing. NCBI reference database accessed on $1^{\text {st }}$ February 2018 was used for the BLAST search (NCBI Resource Coordinators 2016). The BLAST hits from the three sequenced regions combined were used for taxonomy assignment.

Amplification and Library Preparation of Mock Community samples

For each target barcode marker, four separate PCRs were set up, one for each of the three replicates plus a blank sample spiked with MGW. The $5^{\prime}$ ends of each of the primers were tailed with Nextera adapter sequences (Table 2). The reaction conditions were different for each marker (see Suppl. material 1: Table S1). For all the samples, PCR was performed in $25 \mu \mathrm{l}$ reactions containing $1 \times$ Phusion HF buffer (New England Biolabs, Ipswich, MA, USA), 0.2 $\mathrm{mM}$ dNTPs, $0.5 \mu \mathrm{M}$ each of adapter-ligated forward and reverse primers, $1 \mathrm{U}$ of Phusion DNA polymerase (New England Biolabs) and $5 \mu \mathrm{l}$ of template DNA was used.

Following the initial PCR reaction, the amplicons were all purified using Ampure XP Beads (Beckman Coulter, Inc. USA). The purified products were quantified using a Qubit ${ }^{\circledR}$ Fluorometer (Thermo Fisher Scientific, Wilmington, DE, USA). This was then followed by an index PCR where unique dual indices and the Illumina sequencing adapters were attached to each amplicon using Nextera XT index primers (Illumina, San Diego, CA, USA) for amplification (Illumina's 16S Metagenomic Sequencing

Table 2. Primers used for amplification of the target barcode markers. Underlined sections of the sequences represent the Illumina overhang adapters.

\begin{tabular}{|c|c|c|}
\hline Primer & Sequence (from 5' end) & Source \\
\hline Nex_NF1 & SCGTCAGATGTGTATAAGAGACAG GGTGGTGCATGGCCGTTCTTAGTT & Porazinska et al. 2009 \\
\hline Nex_18Sr2b & GTCTCGTGGGCTCGGAGATGTGTATAAGAGACAGTACAAAGGGCAGGGACGTAAT & \\
\hline Nex_SSUF04 & TCGTCGGCAGCGTCAGATGTGTATAAGAGACAG GCTTGTCTCAAAGATTAAGCC & Blaxter et al. 1998 \\
\hline Nex_SSUR22 & GTCTCGTGGGCTCGGAGATGTGTATAAGAGACAGGCCTGCTGCCTTCCTTGGA & \\
\hline Nex_D3FA & TCGTCGGCAGCGTCAGATGTGTATAAGAGACAG GACCCGTCTTGAAACACGGA & Nunn 1992 \\
\hline Nex_D3BR & GTCTCGTGGGCTCGGAGATGTGTATAAGAGACAGCGGAAGGAACCAGCTACTA & \\
\hline Nex_JB3 & TCGTCGGCAGCGTCAGATGTGTATAAGAGACAGTTTTTTGGGCATCCTGAGGTTTAT & \\
\hline Nex_JB5GED & GTCTCGTGGGCTCGGAGATGTGTATAAGAGACAG & Derycke et al. 2010 \\
\hline
\end{tabular}


Library Preparation protocol). PCR was performed in 50 $\mu \mathrm{l}$ reactions containing $5 \mu \mathrm{l}$ each of Nextera XT Index primers 1 and 2, $5 \mu$ l of template DNA, $1 \times$ HF buffer, $0.2 \mathrm{mM}$ dNTPs, $1 \mathrm{mM} \mathrm{MgCl}, 0.5 \mathrm{U}$ Phusion polymerase and $22 \mu \mathrm{MGW}$. The PCR programme was set at $98^{\circ} \mathrm{C}$ for $3 \mathrm{~min}, 8$ cycles of $98^{\circ} \mathrm{C}$ for $30 \mathrm{~s}, 55^{\circ} \mathrm{C}$ for $30 \mathrm{~s}, 72^{\circ} \mathrm{C}$ for $30 \mathrm{~s}$ and a final extension step at $72{ }^{\circ} \mathrm{C}$ for $5 \mathrm{~min}$. A list of samples and the combination of indexes used are provided (Suppl. material 1: Table S2).

The indexed products were purified using Ampure XP Beads, quantified and pooled according to their molarity. After that, the pooled sample was run on an Agilent 2200 TapeStation system (Agilent Technologies, Santa Clara, CA, USA) to verify the size of the pooled amplicons. The pool was quantified and diluted to $4 \mathrm{nM}$ concentration. The library was sequenced on an Illumina MiSeq using $2 \times 300$ cycles V3 run kit.

\section{Analysis of NGS data from mock community samples}

Sequence analyses were performed using USEARCH version 8.1.1861 (Edgar 2010). For each of the barcode marker, the paired reads were merged using the fastq mergepairs command, allowing 15 base mismatches in the aligned region. The merged reads were quality filtered and all reads with more than one base expected errors were removed (Edgar and Flyvbjerg 2015). Details on how the expected error value of a sequence was calculated are described here: https://www.drive5. com/usearch/manual/exp_errs.html. Reads shorter than 250 bp were also discarded using the USEARCH command fastq filter. The filtered reads were dereplicated via fastx_uniques (USEARCH v9.2.64) and then clustered into operational taxonomic units (OTUs) at $97 \%$ similarity cut-off using UPARSE (Edgar 2013) applying the command cluster_otus which removes chimeric reads in the process. To identify cross-talk errors, BLAST search was performed on all the OTUs and the alignment between each query OTU and the reference sequence examined. Any OTU that aligns with the wrong marker or aligns with the wrong position within the gene was flagged as a product of cross-talk error and removed.

\section{Taxonomy assignment}

OTUs were assigned taxonomy based on the utax method within USEARCH. Details on the reference databases are described below. As an alternative to the utax approach, OTUs of each marker were assigned taxonomy using BLAST (Zhang et al. 2000) against sequences in the NCBI nucleotide database (Sayers et al. 2018). The BLAST search was performed using the BLAST+ (Camacho et al. 2009) command line tools with all parameters left at default settings, except for the number of descriptions and alignments which were both set to five. A phylogeny-based assignment method was also performed. For this approach, the reference sequences were first truncated to remove leading and trailing regions outside the primer annealing site of the markers using the USEARCH command search_pcr in order to facilitate alignment. The reference sequences were then combined with the OTUs and aligned using muscle (Edgar 2004), leaving all parameters at default settings. The aligned sequences were trimmed to the length of markers inside MEGA 7 (Kumar et al. 2016). The alignments were used to construct maximum likelihood trees using RAxML version 8.2.10 (Stamatakis 2014) on the CIPRES science gateway web portal (Miller et al. 2010) with GTR as the substitution model at gamma rates distribution. Bootstrap was set to 1000 replicates. Trees were visualized, and labelled within the interactive tree of life (iTOL) web-based tool (Letunic and Bork 2016).

\section{Proportion of reads assigned to nematode OTUs}

Based on the results of the taxonomy assignments from the three approaches, the proportion of filtered reads assigned to nematodes in relation to the total number of reads was determined for each marker. The accuracy of the taxonomic assignment of each marker was determined by comparing the exactness with which each marker recovered the taxa in the mock community at the species or genus level. For sampled taxa whose species identities were known, accurate species identification was expected whereas for the rest, accurate genus identification was expected.

\section{Reference databases for taxonomy}

The reference library for assigning taxonomies to the OTUs generated from the two 18S rDNA markers was obtained from the Protists Ribosomal Reference database, $\mathrm{PR}^{2}$ v 4.72 (Guillou et al. 2012). The database consists of $18 \mathrm{~S}$ ribosomal RNA and DNA sequences, with curated taxonomy of protists and other metazoans including nematodes. The version used contained 4,910 nematode sequences and was last curated on $7^{\text {th }}$ October 2017. Some of the sequences span the locations of both $18 \mathrm{~S}$ rDNA markers used.

For the 28S rDNA, reference sequences were obtained from the SILVA ribosomal RNA gene database (Quast et al. 2013) downloaded on $25^{\text {th }}$ January 2018. Thirteen of the sampled taxa could not be found in this database, hence it was subsequently complemented with respective sequences from GenBank and sequences obtained from the Sanger sequencing in this study (see Suppl. material 1: Table S3). A custom python script (see Suppl. material 2) was used to convert the taxonomies to utax-compatible format as described at http://drive5.com/usearch/ manual/tax_annot.html.

A search through the BOLD database for nematode COI sequences revealed that only nine of the taxa included in the mock community had sequences available for comparison. Similar to the $28 \mathrm{~S}$ rDNA refer- 
ences, sequences of nematode COI were obtained from GenBank (on $25^{\text {th }}$ January 2018) using a command within the statistical assignment package (SAP 1.9.8) (Munch et al. 2008) and formatted for utax taxonomy assignments. After formatting the sequences, only ones matching six of the sampled taxa passed to be part of the database. For the BLAST taxonomy assignments sequences from the NCBI nucleotide database were used as references.

Availability of reference sequences in public databases

For each of the four markers, sequences within four different public databases were used to determine how many nematode sequences actually contain the entire length of region covered by the respective marker. Sequences were downloaded from NCBI nucleotide, SILVA, $\mathrm{PR}^{2}$ and BOLD databases (Table 3). Using the USEARCH command search pcr each sequence was searched for the presence of respective PCR primers of the markers. The number of sequences including the primer regions were retained and counted. The number of unique nematode genera represented in the retained sequences were determined and compared for each marker.

Taxonomic coverage and abundance prediction

The markers were compared on the basis of how well they predicted the mock community both qualitatively and quantitatively. The qualitative prediction was based on how many taxa in the mock community were recovered while the quantitative predictions were based on the coefficient of determination $\left(r^{2}\right)$ of the linear regression between the average relative read frequencies and relative abundances. Similarities in the abundance estimates between the replicates were also shown by the standard deviations of their relative read frequencies and their correlation coefficients.

\section{Results}

\section{Single specimens}

BLAST searches were performed on the sequences of all three genomic regions that were analysed using the Sanger method against NCBI nucleotide database. This confirmed the morphological identifications of almost all the individuals. The only individuals whose identities could not be confirmed were the morphologically identified Criconema and Acrobeloides sp. (Table 4). Sequences were not obtained from any of the markers for these taxa, which was not surprising because none of the markers produced strong PCR bands for these taxa on the gel. The COI sequences were of poor quality. Therefore, after trimming, only sequences of Plectus sp. had sufficient overlap to allow for merging. In addition, six other sequences in only one orientation remained after trimming.
Table 3. Databases from which nematode sequences were downloaded for each of the four markers.

\begin{tabular}{|c|c|c|c|c|}
\hline Database & NF1-18Sr2b & $\begin{array}{l}\text { SSUF04- } \\
\text { SSUR22 } \\
\end{array}$ & D3Af-D3Br & JB3-JB5ED \\
\hline $\begin{array}{l}\text { NCBI nucleotide } \\
\text { (18S, 28S rDNA, } \\
\text { COI) }\end{array}$ & $X$ & $\mathrm{X}$ & $\mathrm{X}$ & $\mathrm{X}$ \\
\hline $\begin{array}{l}\text { SILVA (18S, } \\
28 \mathrm{~S} \text { rDNA) }\end{array}$ & $\mathrm{X}$ & $\mathrm{X}$ & $\mathrm{X}$ & \\
\hline $\mathrm{PR}^{2}$ (18S rDNA) & $\mathrm{X}$ & $\mathrm{X}$ & & \\
\hline BOLD (COI) & & & & $\mathrm{X}$ \\
\hline
\end{tabular}

Table 4. Confirmed identities of individuals included in the mock communities. Sequences of the three DNA regions were analysed using the Sanger method. X denotes positive identification.

\begin{tabular}{|c|c|c|c|c|}
\hline Samples & Morphology & $\begin{array}{c}18 \mathrm{~S} \\
\text { region }\end{array}$ & $\begin{array}{c}28 \mathrm{~S} \\
\text { region }\end{array}$ & $\begin{array}{c}\mathrm{COI} \\
\text { region }\end{array}$ \\
\hline Specimen 1 & Hemicycliophora sp. & & $\mathrm{X}$ & \\
\hline Specimen 2 & Ditylenchus dipsaci & $\mathrm{X}$ & $\mathrm{X}$ & \\
\hline Specimen 3 & Aporcelaimellus sp. & $\mathrm{X}$ & $\mathrm{X}$ & \\
\hline Specimen 4 & Anatonchus tridentatus & $\mathrm{X}$ & $\mathrm{X}$ & \\
\hline Specimen 5 & Globodera rostochiensis & $X$ & $X$ & \\
\hline Specimen 6 & Trichodorus primitivus & $\mathrm{X}$ & $\mathrm{X}$ & \\
\hline Specimen 7 & Rhabditis sp. & $\mathrm{X}$ & $\mathrm{X}$ & \\
\hline Specimen 8 & Prionchulus punctatus & $X$ & $\mathrm{X}$ & \\
\hline Specimen 9 & Criconema sp. & & & \\
\hline Specimen 10 & Tripyla sp. & $\mathrm{X}$ & $\mathrm{X}$ & \\
\hline Specimen 11 & Pristionchus sp. & $\mathrm{X}$ & $\mathrm{X}$ & \\
\hline Specimen 12 & Anaplectus sp. & & $\mathrm{X}$ & \\
\hline Specimen 13 & Acrobeles sp. & & $\mathrm{X}$ & \\
\hline Specimen 14 & Acrobeloides sp. & & & \\
\hline Specimen 15 & Steinernema carpocapsae & $\mathrm{X}$ & $\mathrm{X}$ & \\
\hline Specimen 16 & Plectus sp. & $\mathrm{X}$ & $\mathrm{X}$ & $\mathrm{X}$ \\
\hline Specimen 17 & Xiphinema diversicaudatum & $\mathrm{X}$ & $\mathrm{X}$ & \\
\hline Specimen 18 & Longidorus caespiticola & $\mathrm{X}$ & $\mathrm{X}$ & \\
\hline Specimen 19 & Alaimus sp. & $\mathrm{X}$ & $\mathrm{X}$ & \\
\hline Specimen 20 & Tylenchus sp. & & $\mathrm{X}$ & \\
\hline Specimen 21 & Aphelenchoides sp. & $\mathrm{X}$ & $\mathrm{X}$ & \\
\hline
\end{tabular}

Because of this and the fact that there were not enough sequences of the COI region in NCBI nucleotide database to search the sequences against, only Plectus sp. could be confirmed by this region. The D2-D3 region produced amplicons for all except the two missing taxa and was able to confirm the identities of all the taxa with amplicons. The two fragments of the $18 \mathrm{~S}$ rDNA together also identified fifteen of the twenty-one specimens.

\section{Sequence reads from mock community}

The sequence reads were demultiplexed by the MiSeq Reporter software (MiSeq ${ }^{\circledR}$ Reporter Software Guide, Illumina, Inc., San Diego, CA, USA; Document \# 15042295 v05) using default settings (allowing one mismatch in the indexes). Blank samples only yielded sequences of fungi and streptophyta. A summary of the number of reads generated for each marker from each of the three repli- 
cates is presented in Table 5. Read numbers between the replicates of the NF1-18Sr2b samples were similar. The highest variability between the replicates was found for the markers SSUF04-SSUR22 and JB3-JB5GED.

\section{Merged reads and sequence quality}

The JB3-JB5 marker was the only region for which more than half $(57 \%)$ of the paired reads were successfully merged. The marker with lowest percentage of merged reads was the SSUF04-SS0R22 (38\%). Despite the low percentage of merged reads recovered for NF1-18Sr2b and D3Af-D3Br, the percentage of reads that passed the quality filtering step were much higher than that of the JB3-JB5ED marker (Table 6).

\section{Reference database coverage}

Major differences were observed for the coverage of the $18 \mathrm{~S}$ rDNA-based markers, namely NF1-18Sr2b and SSUF04-SSUR22 across all three 18S rDNA databases (Figure 1). The total number of unique nematode genera covered by the NF1-18Sr2b marker ranged from 550 to 700 , compared to 110 to 150 for the SSUF04-SSUR22. The 28S rDNA-based D3Af-D3Br marker also covered slightly more genera than the SSUF04-SSUR22. The COI-based JB3-JB5ED marker covered the fewest genera, although not markedly lower than SSUF04-SSUR22.

\section{Taxonomy assignment via utax}

With the utax method, only those genera assigned with support (posterior probability) values of 0.5 or higher were considered valid in this study (Table 7). For the NF1-18Sr2b marker, 23 OTUs produced valid assignments and they accounted for fourteen of the sampled taxa $(61 \%)$. The results also revealed a phenomenon encountered in some of the curated public databases. It was observed that some of the entries had incomplete taxonomies or ambiguous descriptions, as pointed out previously (Holovachov et al. 2017). Several of the OTUs could not be assigned taxonomy because their best hits were either 'uncultured eukaryote', 'environmental nematode', 'Chromadorea_X' or 'Enoplea_X'. This was seen in the markers that were assigned taxonomy with either the $\mathrm{PR}^{2}$ or SILVA reference sequences.

Using the utax method with the $\mathrm{PR}^{2}$ database, only eight OTUs of the SSUF04-SSUR22 marker were identified as nematodes, which accounted for only five of the sampled taxa (22\%). The majority of the OTUs were not given taxonomic assignments, at least not with sufficient support for them to be considered valid.

For the 28S rDNA marker (D3Af-D3Br), only 22 of the total 144 OTUs were successfully assigned nematode identities and this accounted for eight of the sampled taxa (34\%).

The COI marker (JB3-JB5GED) was the only marker for which no successful taxonomic assignments were achieved at the genus level. Only three OTUs were iden-
Table 5. Number of sequence reads generated for each of the markers across the three mock community replicates with standard error of means of the replicate samples.

\begin{tabular}{lcccc}
\hline \multirow{1}{*}{ Samples } & \multicolumn{4}{c}{ Number of reads } \\
\cline { 2 - 5 } & $\begin{array}{c}\text { NF1- } \\
\text { 18Sr2b }\end{array}$ & $\begin{array}{c}\text { SSUF04- } \\
\text { SSUR22 }\end{array}$ & $\begin{array}{c}\text { D3Af- } \\
\text { D3Br }\end{array}$ & $\begin{array}{c}\text { JB3- } \\
\text { JB5GED }\end{array}$ \\
\hline $\begin{array}{l}\text { Replicate 1 } \\
\text { (MC1) }\end{array}$ & $2,483,453$ & $3,162,379$ & $3,897,994$ & $1,236,201$ \\
$\begin{array}{l}\text { Replicate 2 } \\
\text { (MC2) }\end{array}$ & $2,349,364$ & $2,790,363$ & $4,228,233$ & $2,160,885$ \\
$\begin{array}{l}\text { Replicate 3 } \\
\text { (MC3) }\end{array}$ & $2,435,278$ & $1,953,138$ & $4,309,817$ & $1,204,900$ \\
$\begin{array}{l}\text { Standard error } \\
\text { of mean }\end{array}$ & 39,216 & 357,585 & 125,899 & 377,501 \\
\hline
\end{tabular}

Table 6. Summary of analysis results for each of the four markers.

\begin{tabular}{lcccc}
\hline \multicolumn{1}{c}{ Marker } & $\begin{array}{c}\text { Reads } \\
\text { successfully } \\
\text { merged (\%) }\end{array}$ & $\begin{array}{c}\text { Merged } \\
\text { reads passing } \\
\text { filtering (\%) }\end{array}$ & $\begin{array}{c}\text { Number } \\
\text { of OTUs }\end{array}$ & $\begin{array}{c}\text { Chimeric } \\
\text { sequences }\end{array}$ \\
\hline NF1-18Sr2b & 48.3 & 96.7 & 138 & 5,677 \\
SSUF04- & 38.0 & 88.9 & 161 & 6,813 \\
SSUR22 & & & & \\
D3Af-D3Br & 43.1 & 98.4 & 144 & 3,295 \\
JB3-JB5GED & 57.0 & 64.3 & 69 & 1,830 \\
\hline
\end{tabular}

Table 7. List of taxa recovered using the utax taxonomy assignment. For NF1-18Sr2b and SSUF04-SSUR22, the PR2 database was used as reference database and for D3Af-D3Br, combined nematode sequences from NCBI nucleotide database, sequences from this study and SILVA database were used. For JB3-JB5GED, sequences from NCBI nucleotide database, sequences from this study and the BOLD database were used.

\begin{tabular}{|c|c|c|c|}
\hline NF1-18Sr2b & SSUF04-SSUR22 & D3Af-D3Br & JB3-JB5GED \\
\hline Alaimus sp. & & & Rhabditida \\
\hline Anaplectus sp. & & & Tylenchida \\
\hline \multirow[t]{2}{*}{$\begin{array}{l}\text { Aphelenchoides } \\
\text { ritzemabosi }\end{array}$} & & $\begin{array}{c}\text { Aphelenchoides } \\
\text { gorganensis }\end{array}$ & \\
\hline & & $\begin{array}{c}\text { Ditylenchus } \\
\text { dipsaci }\end{array}$ & \\
\hline Globodera & Globodera & $\begin{array}{l}\text { Globodera } \\
\text { ellingtonae }\end{array}$ & \\
\hline $\begin{array}{l}\text { Hemicycliophora } \\
\text { conida }\end{array}$ & & $\begin{array}{c}\text { Hemicycliophora } \\
\text { wyei }\end{array}$ & \\
\hline \multicolumn{4}{|l|}{$\begin{array}{l}\text { Laimaphelenchus } \\
\text { penardi }\end{array}$} \\
\hline Longidorus & Longidorus & $\begin{array}{l}\text { Longidorus } \\
\text { macrosoma }\end{array}$ & \\
\hline \multirow[t]{2}{*}{$\begin{array}{l}\text { Meloidogyne } \\
\text { hapla }\end{array}$} & & $\begin{array}{l}\text { Meloidogyne } \\
\text { hapla }\end{array}$ & \\
\hline & Prionchulus & & \\
\hline \multicolumn{4}{|l|}{ Pristionchus } \\
\hline Rhabditis & Rhabditis & Rhabditis sp. & \\
\hline \multirow[t]{2}{*}{ Steinernema } & Steinernema & & \\
\hline & & $\begin{array}{l}\text { Trichodorus } \\
\text { primitivus }\end{array}$ & \\
\hline \multicolumn{4}{|l|}{ Tripyla sp. } \\
\hline \multicolumn{4}{|l|}{$\begin{array}{l}\text { Tylenchus } \\
\text { arcuatus }\end{array}$} \\
\hline Xiphinema & & & \\
\hline
\end{tabular}




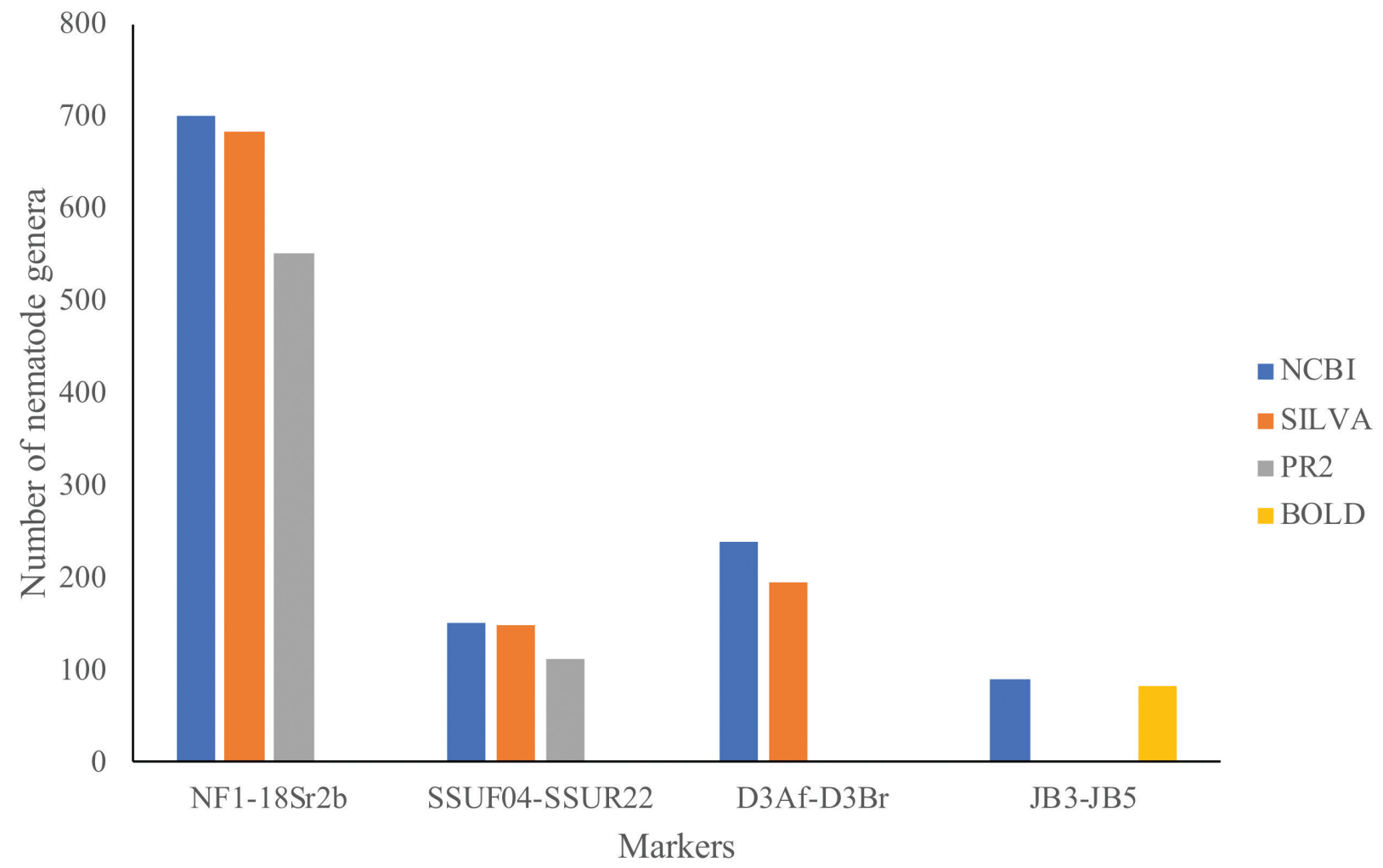

Figure 1. Number of nematode genera with sequences of the markers available in NCBI nucleotide database, SILVA, PR2 and BOLD databases.

tified as nematodes and could only be correctly identified to the order rank. Two of the OTUs matched Rhabditida and the other one Tylenchida (according to the classification by Siddiqi (2000)).

With the exception of a few, most of the recovered taxa occurred in all three replicates for all the markers (Suppl. material 1: Table S4). For NF1-18Sr2b, only two of the fourteen recovered taxa failed to occur in each of the replicates; similarly, only one for SSUF04SSUR22, two for D3Af-D3Br and for JB3-JB5GED, only one.

\section{Taxonomy assignment via BLAST search against the NCBI Nucleotide Database}

The OTUs generated for each of the markers were used to perform a BLAST search against the NCBI Nucleotide Database on $16^{\text {th }}$ July 2017 . Only alignments with expect $(E)$ values less than 0.001 were considered. The top hits were examined for matches that had complete taxonomies, and only matches with an identity $\geq 95 \%$ were considered. Based on these criteria, all OTUs of the NF1-18Sr2b marker matched taxonomically assigned sequences in the NCBI nucleotide sequences. All sampled taxa were recovered with the BLAST method for NF1-18Sr2b marker, at least to the genus level (Table 8). For most of the OTUs the $E$ values of the alignments were zero. All non-nematode matches were ignored.
The SSUF04_SSUR22 marker failed to recover nine of the sampled taxa (Acrobeles, Acrobeloides, Aphelenchoides, Aporcelaimellus, Criconema, Hemicycliophora, Laimaphelenchus, Plectus and Tylenchus) either due to no match or identities below $95 \%$. This marker also produced some hits that were not nematodes. OTUs of the D3Af-D3Br marker had matches for all of the sampled taxa except Anaplectus and Criconema. As with the other markers, there were some non-nematode hits. The JB3-JB5GED OTUs had a slight improvement with this method over the utax assignment. Unlike the utax taxonomy assignment which gave no assignments below the order level for this marker, the BLAST method was able to recover two of the sampled taxa, Meloidogyne hapla and Steinernema carpocapsae. Three OTUs were identified as cross-talk errors and subsequently removed. Almost all taxa recovered by the markers were detected across all three replicates (Suppl. material 1: Table 5). In the NF1-18Sr2b samples, only three out of the twenty-three taxa failed to appear in all three replicates: Criconema and Anaplectus occurred in two replicates while Alaimus occurred only in one. For SSUF04SSUR22 and JB3-JB5GED all recovered taxa were found in each of the replicates. Of the 19 recovered taxa in the D3Af-D3Br samples, there were only two taxa that failed to occur in all replicates: Hemicycliophora wyei was only found in one replicate while Acrobeles complexus occurred in two replicates. 
Table 8. List of taxa recovered based on BLAST searches. All searches were performed against the NCBI nucleotide database. Only taxonomic assignments appearing in top five hits and had similarities $\geq 95 \%$, e value $<0.001$ were considered.

\begin{tabular}{|c|c|c|c|}
\hline NF1-18Sr2b & SSUF04-SSUR22 & D3Af-D3Br & JB3-JB5GED \\
\hline Alaimus sp. & Alaimus sp. & Alaimus sp. & \\
\hline Anaplectus sp. & Anaplectus sp. & & \\
\hline $\begin{array}{l}\text { Anatonchus } \\
\text { tridentatus }\end{array}$ & $\begin{array}{l}\text { Anatonchus } \\
\text { tridentatus }\end{array}$ & $\begin{array}{l}\text { Anatonchus } \\
\text { tridentatus }\end{array}$ & \\
\hline $\begin{array}{l}\text { Aphelenchoides } \\
\text { ritzemabosi }\end{array}$ & & $\begin{array}{c}\text { Aphelenchoides } \\
\text { ritzemabosi }\end{array}$ & \\
\hline $\begin{array}{l}\text { Aporcelaimellus } \\
\text { obtusicaudatus }\end{array}$ & & $\begin{array}{l}\text { Aporcelaimellus } \\
\text { obtusicaudatus }\end{array}$ & \\
\hline Acrobeles sp. & & $\begin{array}{l}\text { Acrobeles } \\
\text { complexus }\end{array}$ & \\
\hline Acrobeloides sp. & & Acrobeloides sp. & \\
\hline \multicolumn{4}{|l|}{ Criconema sp. } \\
\hline $\begin{array}{l}\text { Ditylenchus } \\
\text { dipsaci }\end{array}$ & $\begin{array}{l}\text { Ditylenchus } \\
\text { dipsaci }\end{array}$ & $\begin{array}{l}\text { Ditylenchus } \\
\text { dipsaci }\end{array}$ & \\
\hline $\begin{array}{l}\text { Globodera } \\
\text { rostochiensis }\end{array}$ & $\begin{array}{l}\text { Globodera } \\
\text { rostochiensis }\end{array}$ & Globodera sp. & \\
\hline $\begin{array}{l}\text { Hemicycliophora } \\
\text { conida }\end{array}$ & & $\begin{array}{c}\text { Hemicycliophora } \\
\text { wyei }\end{array}$ & \\
\hline $\begin{array}{l}\text { Laimaphelenchus } \\
\text { penardi }\end{array}$ & & $\begin{array}{c}\text { Laimaphelenchus } \\
\text { deconincki }\end{array}$ & \\
\hline $\begin{array}{l}\text { Longidorus } \\
\text { caespiticola }\end{array}$ & $\begin{array}{l}\text { Longidorus } \\
\text { caespiticola }\end{array}$ & $\begin{array}{l}\text { Longidorus } \\
\text { macrosoma }\end{array}$ & \\
\hline $\begin{array}{l}\text { Meloidogyne } \\
\text { hapla }\end{array}$ & $\begin{array}{l}\text { Meloidogyne } \\
\text { hapla }\end{array}$ & $\begin{array}{l}\text { Meloidogyne } \\
\text { hapla }\end{array}$ & $\begin{array}{l}\text { Meloidogyne } \\
\text { hapla }\end{array}$ \\
\hline $\begin{array}{l}\text { Plectus } \\
\text { andrassyi }\end{array}$ & & Plectus sp. & \\
\hline $\begin{array}{l}\text { Prionchulus } \\
\text { punctatus }\end{array}$ & $\begin{array}{l}\text { Prionchulus } \\
\text { punctatus }\end{array}$ & Prionchulus sp. & \\
\hline $\begin{array}{l}\text { Pristionchus } \\
\text { lheritieri }\end{array}$ & $\begin{array}{l}\text { Pristionchus } \\
\text { lheritieri }\end{array}$ & $\begin{array}{l}\text { Pristionchus } \\
\quad \text { lucani }\end{array}$ & \\
\hline $\begin{array}{l}\text { Rhabditis cf. } \\
\text { terricola }\end{array}$ & $\begin{array}{l}\text { Rhabditis cf. } \\
\text { terricola }\end{array}$ & Rhabditis sp. & \\
\hline $\begin{array}{l}\text { Steinernema } \\
\text { carpocapsae }\end{array}$ & $\begin{array}{l}\text { Steinernema } \\
\text { carpocapsae }\end{array}$ & $\begin{array}{l}\text { Steinernema } \\
\text { carpocapsae }\end{array}$ & $\begin{array}{l}\text { Steinernema } \\
\text { carpocapsae }\end{array}$ \\
\hline $\begin{array}{l}\text { Trichodorus } \\
\text { primitivus }\end{array}$ & $\begin{array}{l}\text { Trichodorus } \\
\text { primitivus }\end{array}$ & $\begin{array}{l}\text { Trichodorus } \\
\text { primitivus }\end{array}$ & \\
\hline $\begin{array}{l}\text { Tripyla } \\
\text { glomerans }\end{array}$ & $\begin{array}{l}\text { Tripyla } \\
\text { glomerans }\end{array}$ & Tripyla sp. & \\
\hline $\begin{array}{l}\text { Tylenchus } \\
\text { arcuatus }\end{array}$ & & $\begin{array}{c}\text { Tylenchus } \\
\text { naranensis }\end{array}$ & \\
\hline Xiphinema sp. & $\begin{array}{c}\text { Xiphinema } \\
\text { diversicaudatum }\end{array}$ & $\begin{array}{c}\text { Xiphinema } \\
\text { diversicaudatum }\end{array}$ & \\
\hline
\end{tabular}

\section{Taxonomy assignment using phylogenetic analyses}

The NF1-18Sr2b-based tree placed most of the OTUs together with taxonomically assigned sequences from NCBI nucleotide database within the same clades (Figure 2). The results of the tree-based assignments were very similar to the BLAST approach, with at least 22 out of the 23 taxa identified. Criconema was the only taxon whose OTUs from the NF1-18Sr2b marker were not assigned the expected taxonomy. Instead, the OTU that matched Criconema from the BLAST search clustered with Ogma and Bakernema, both of which are close phylogenetic relatives of Criconema. From the SSUF04-SSUR22-tree, only four of the sampled taxa could be correctly identified (Figure 3). For the D3AfD3Br marker OTUs of 16 of the sampled taxa were identified using phylogenetic methods (Figure 4). With the JB3-JB5GED-based tree, four clades could be identified that were monophyletic but only three could be used to identify OTUs to the genus level. The OTUs clustered with these three genera: Steinernema, Longidorus and Meloidogyne (Figure 5).

\section{Taxonomic coverage}

The calculation of taxonomic coverage of the markers was based on how many of the sampled taxa were recovered by at least one of the three replicates. This was based on a consensus of the results of the taxonomy assignment via utax, BLAST and the phylogenetic analysis. The NF1-18Sr2b had the highest coverage, producing 100\% recovery of the sampled taxa (Table 9). All 23 taxa were detected in all three replicates, apart from Acrobeles and Criconema. They both failed to appear in one of the replicates. By combining the three methods, the number of correctly classified OTUs for this marker increased from the 23 obtained with $u$ tax to 41 . This represented $97.5 \%$ of the total filtered sequence reads.

In the case of the SSUF04-SSUR22 marker, eight taxa were missing from all three assignment methods. The taxa that were recovered occurred in all three replicates. With all three methods of taxonomy assignment combined, the number of correctly assigned OTUs improved to 56 . The proportion of the total reads that were accurately assigned to nematodes was $94.2 \%$.

The 28S rDNA-based D3Af-D3Br marker assigned 70 OTUs to nematodes and recovered all taxa except Criconema in the consensus taxonomy. Amongst the recovered taxa, Hemicycliophora occurred in one of the replicates, Acrobeles in two, while the rest were found in all three replicates. The proportion of the filtered reads correctly assigned to nematodes with this marker was $95.5 \%$.

For the COI-based JB3-JB5GED marker, even the consensus taxonomy drawn from all three assignment methods could only recover two taxa, namely Meloidogyne and Steinernema. Although the phylogenetic analysis included Longidorus in the assignment, it was discovered that OTU17 and the NCBI reference sequence KJ741245 Longidorus sp., which were clustered together had very low percentage similarity (81\%), considering the $95 \%$ minimum set for the BLAST method. In general, the consensus taxonomies for all the markers were almost exactly as what the BLAST search produced. This is because all successful assignments made by utax against the references were also positive in the BLAST search against the nucleotide database, which detected even more taxa that were missing in the utax results. Even though only two genera could be recovered, a very high percentage of the filtered reads $(92.8 \%)$ belonged to nematodes. 


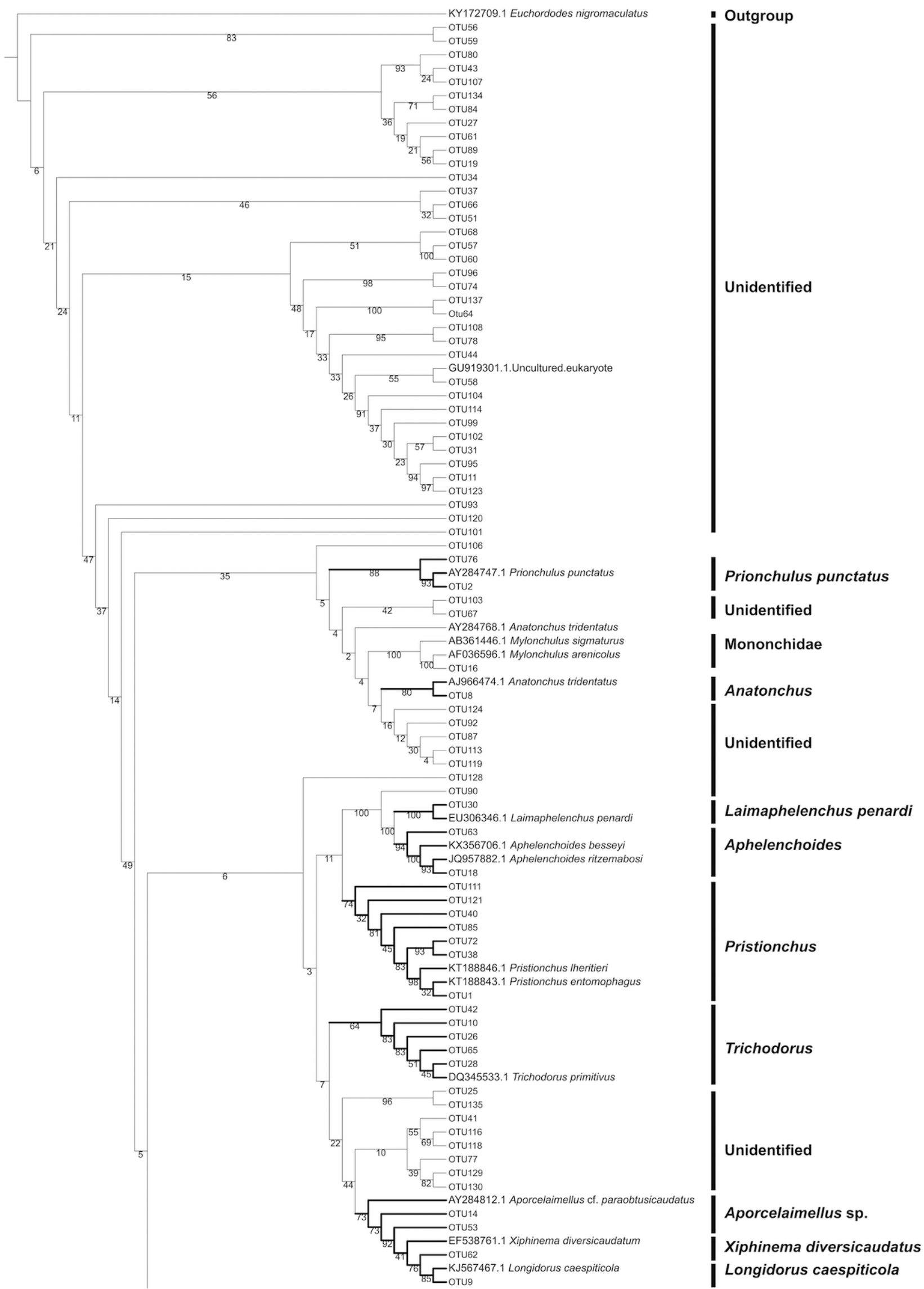

Figure 2. Maximum likelihood tree of the 18S rDNA-based NF1-18Sr2b OTUs and reference sequences from NCBI nucleotide database. 


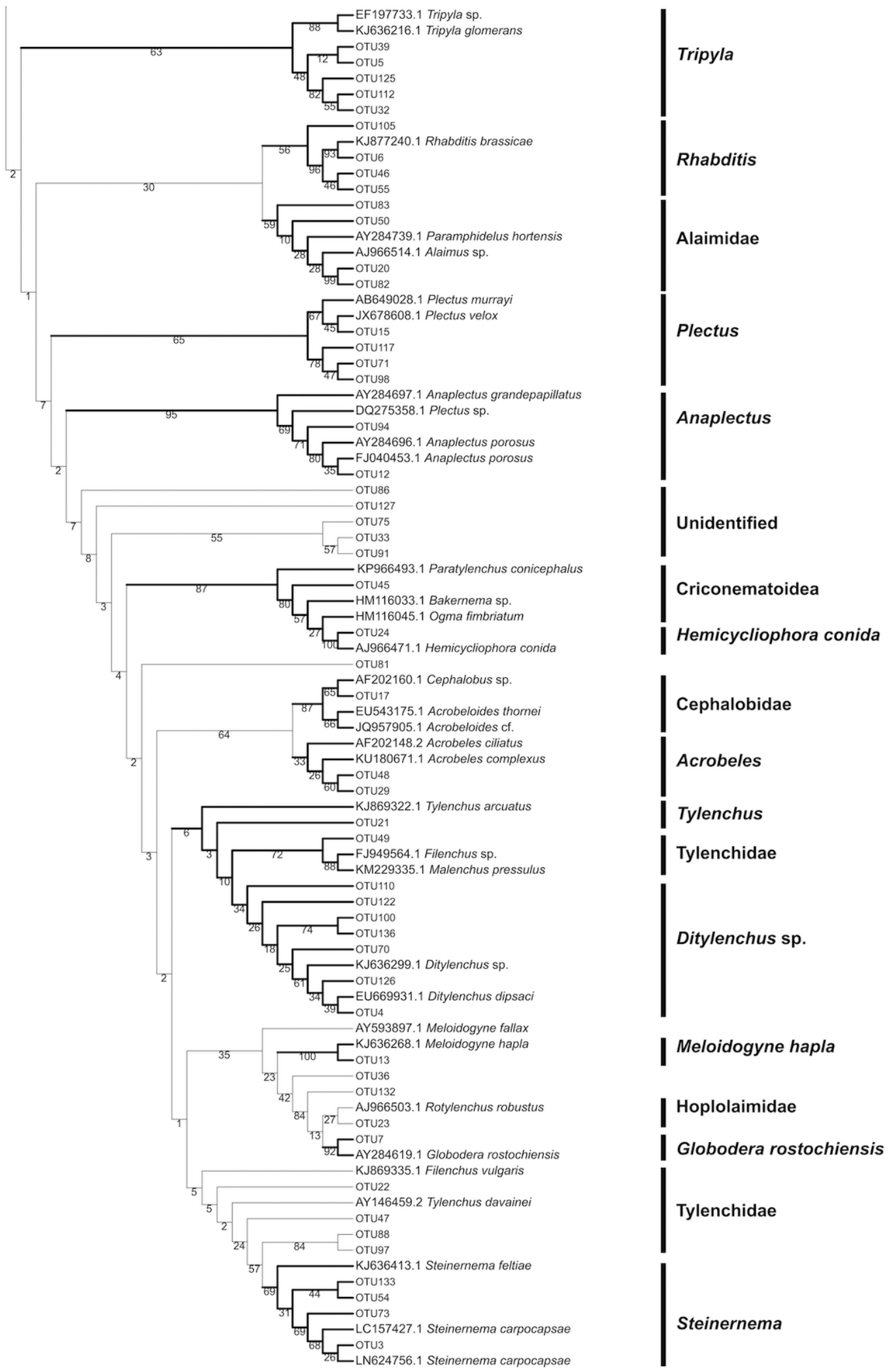

Figure 2. Continued..

\section{Read frequencies and abundance (number of individuals)}

None of the four markers provided a signification correlation between relative read frequency and relative abundance of taxa in the mock community (Suppl. material 1: Table S6). The relative read frequencies between the replicates, however, revealed a strong correlation between replicates for all markers except the COI-based JB3-B53D (Suppl. material 1: Table S6). For the NF1- 


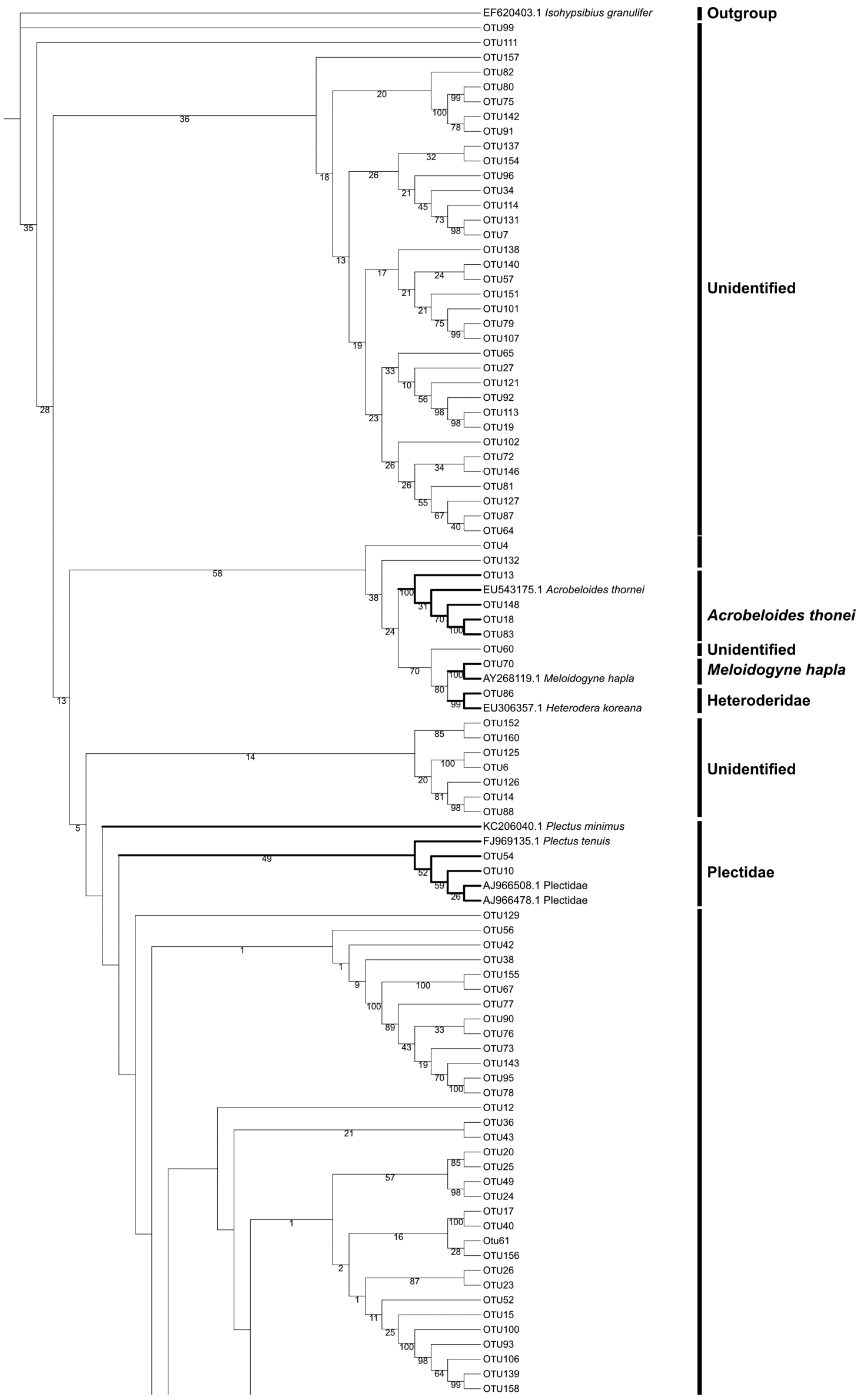

Figure 3. Maximum likelihood tree of the 18S rDNA-based SSUF04-SSUR22 OTUs and reference sequences from NCBI nucleotide database. 


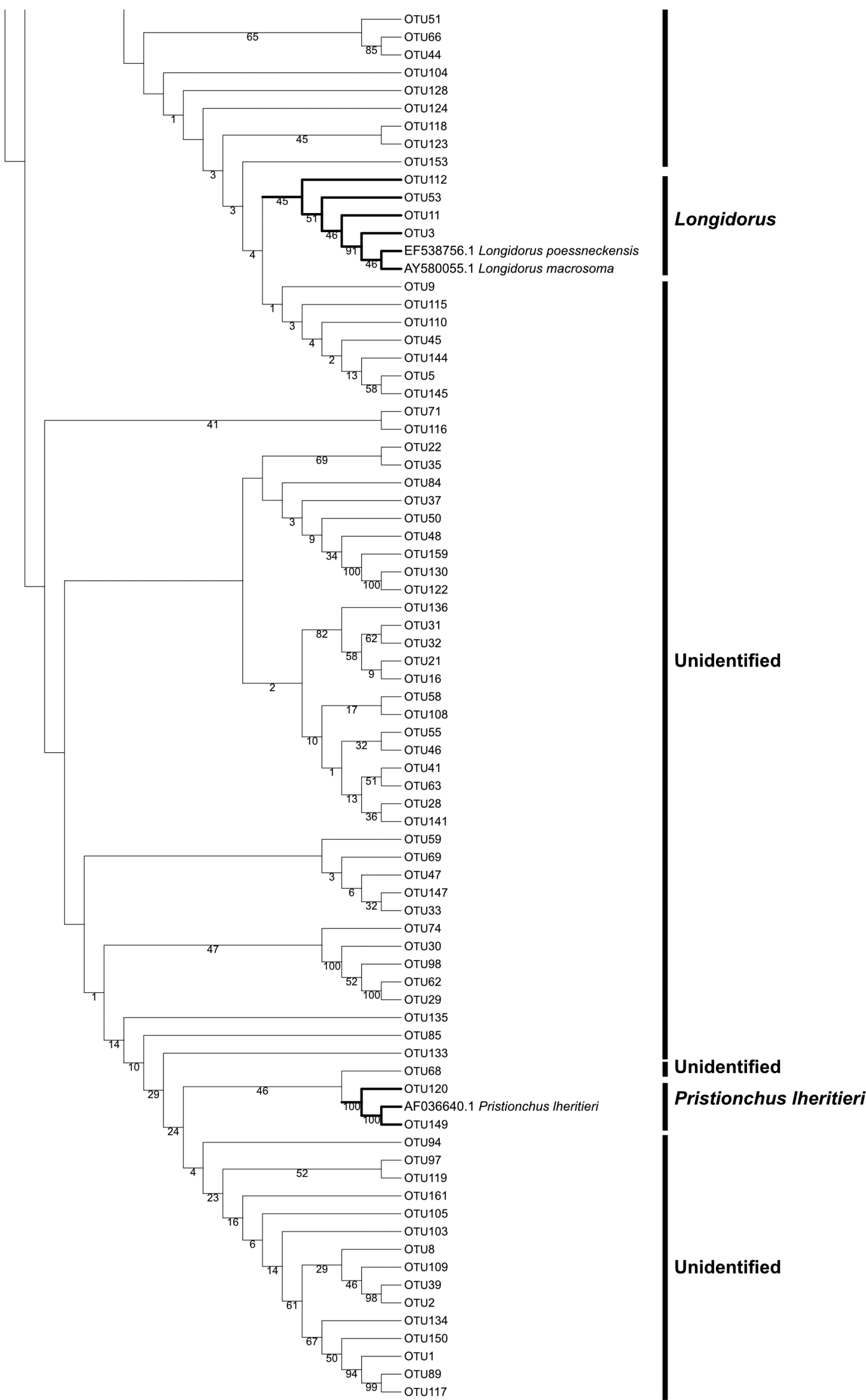

Figure 3. Continued.

18Sr2b marker, Ditylenchus, Prionchulus, Pristionchus and Rhabditis were overrepresented (Figure 6). The most extreme deviation between relative read frequencies and relative abundance was observed in Prionchulus.
The relative number of reads associated with Xiphinema, Trichodorus and Aporcelaimellus were similar to their relative abundances in the mock community. In the case of the SSUF04-SSUR33 marker, Prionchulus and 


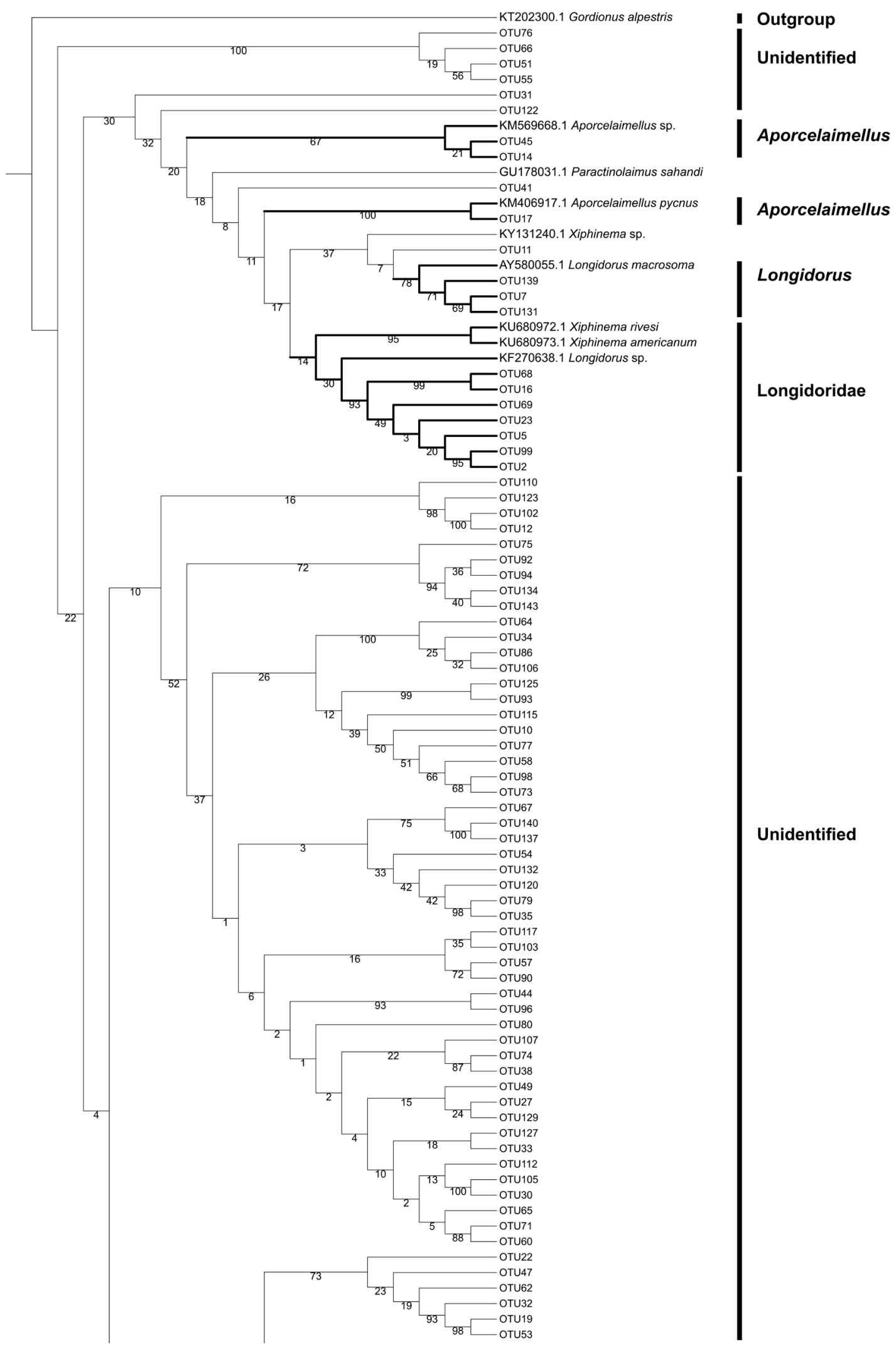

Figure 4. Maximum likelihood tree of the 28S rDNA-based D3Af-D3Br OTUS and reference sequences from NCBI nucleotide database.

Anatonchus were also extremely overrepresented, thus showing strong deviation between their relative read frequencies and their relative abundance. With this marker, the relative read frequencies of Acrobeloides, Alaimus and Tripyla were quite similar to their relative abundanc- es. Relative frequencies of the D3Af-D3Br reads generated for Tripyla, Rhabditis and Prionchulus also deviated significantly from their respective relative abundances. The relative read frequencies of Xiphinema and Acrobeloides were similar to their respective relative abun- 


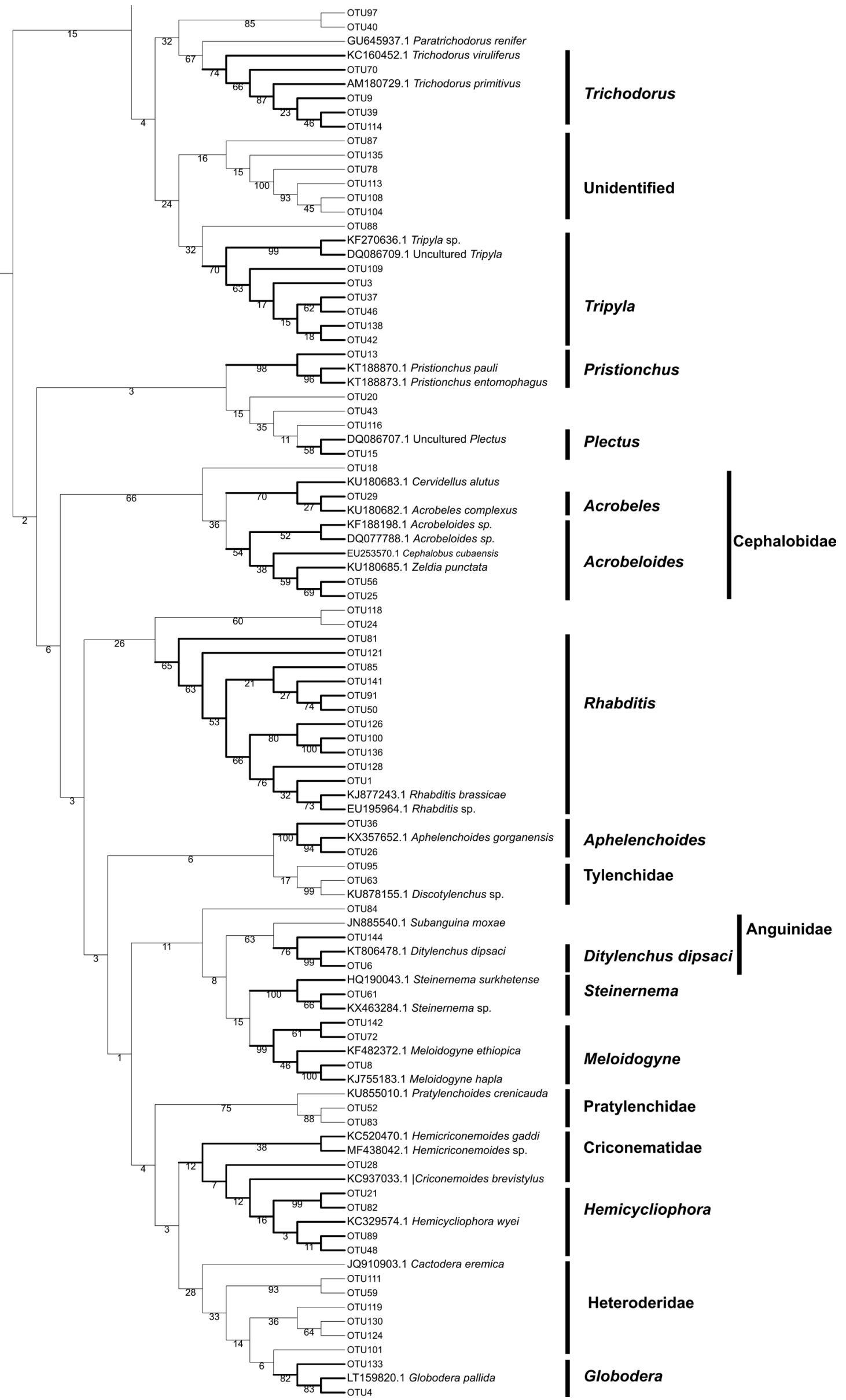

Figure 4. Continued. 


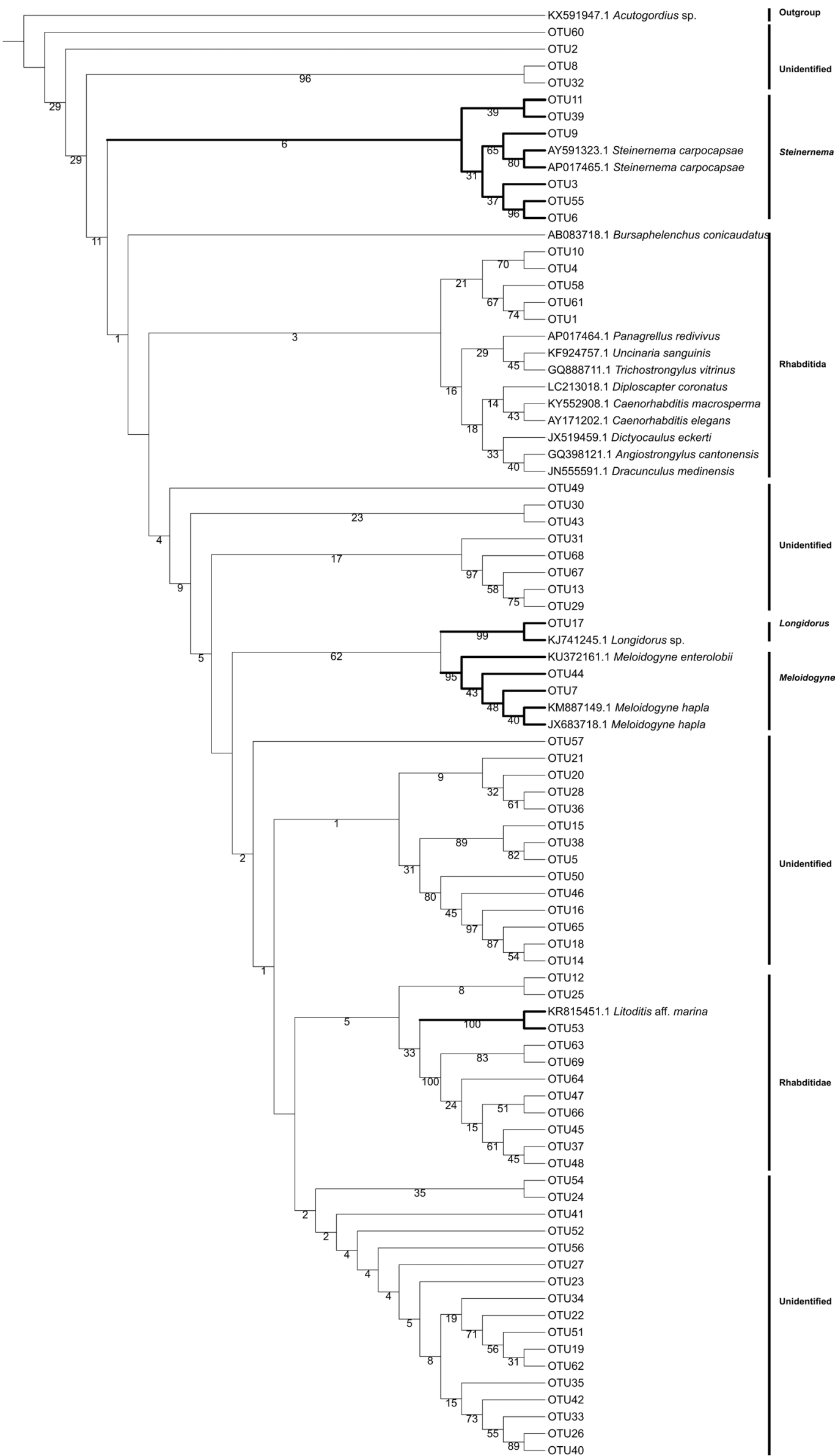

Figure 5. Maximum likelihood tree of the COI-based JB3-JB5ED OTUs and reference sequences from NCBI nucleotide database. 

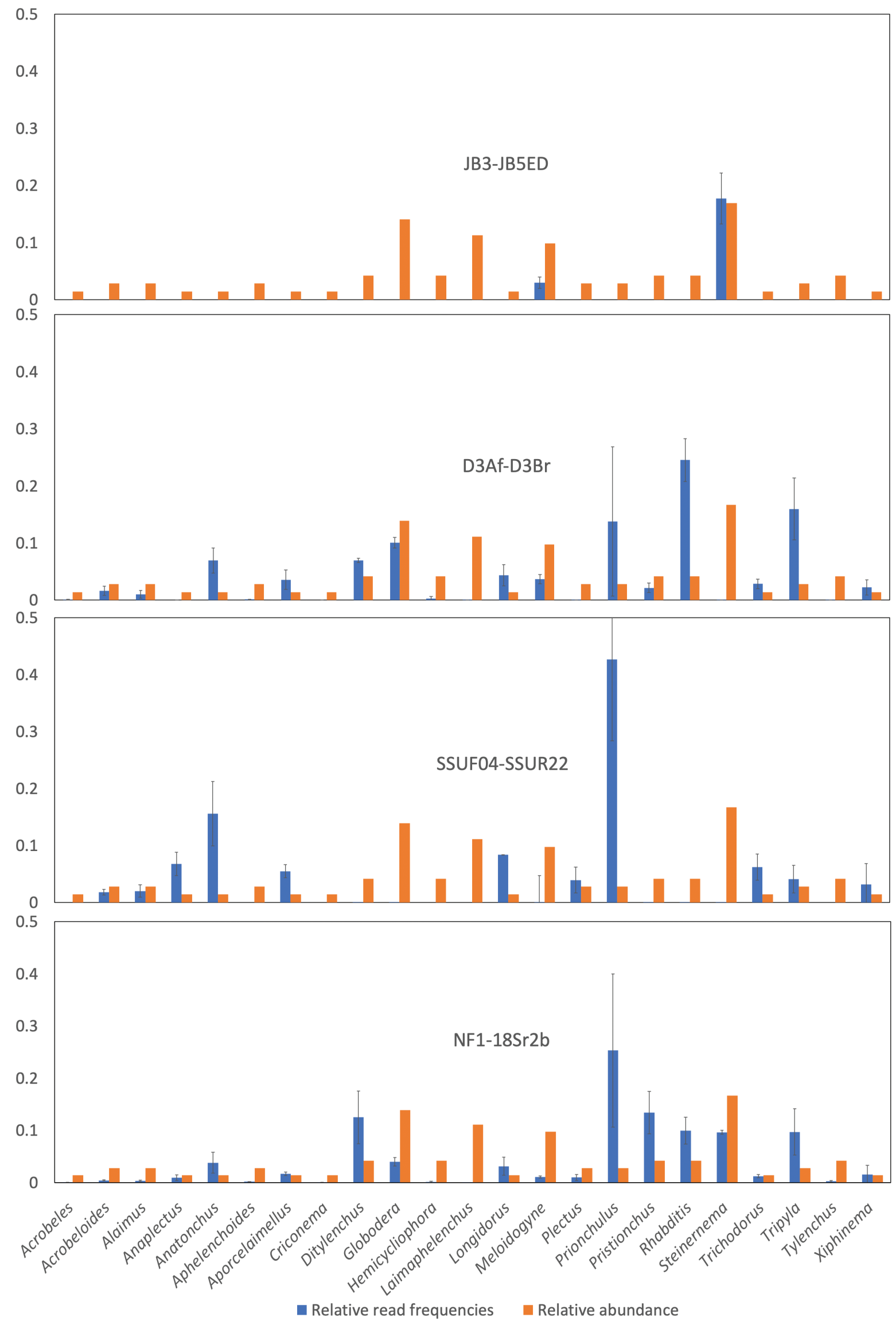

Figure 6. Comparison of the relative read frequencies and relative abundances of sampled taxa. Relative read frequencies are averages of the three replicates and error bars represent their standard deviations. Vertical axis represents proportion of the total number of reads or number of individuals. Blue bars represent relative read frequencies and orange bars represent relative abundance in the mock community. 
Table 9. Taxa recovered by the markers in at least one of the replicates from the three taxonomy assignment methods used. The number of $\mathrm{X}$ indicates the number of replicates in which the taxon was detected. RefSeq denotes the availability of reference sequences for taxonomy assignment of NGS reads.

\begin{tabular}{|c|c|c|c|c|c|c|c|c|}
\hline \multirow[t]{2}{*}{ Taxa in mock community } & \multicolumn{2}{|c|}{ NF1-18Sr2b } & \multicolumn{2}{|c|}{ SSUF04-SSUR22 } & \multicolumn{2}{|c|}{ D3Af-D3Br } & \multicolumn{2}{|c|}{ JB3-JB5GED } \\
\hline & Coverage & RefSeq & Coverage & RefSeq & Coverage & RefSeq & Coverage & RefSeq \\
\hline Alaimus sp. & X X X & Available & X X X & $\uparrow$ Available & X X X & Available & & \\
\hline Trichodorus primitivus & X X X & Available & XXX & $†$ Available & X X X & Available & & \\
\hline Tripyla glomerans & X X X & Available & X X X & $†$ †vailable & X X X & Available & & \\
\hline Longidorus caespiticola & X X X & Available & X X X & *Available & X X X & Available & & Available \\
\hline Xiphinema diversicaudatum & X X X & Available & XXX & $†$ Available & X X X & **Available & & *Available \\
\hline Aporcelaimellus sp. & X X X & Available & & †Available & X X X & Available & & \\
\hline Prionchulus punctatus & X X X & Available & XXX & †Available & X X X & Available & & \\
\hline Anatonchus tridentatus & X X X & Available & X X X & $\dagger$ Available & X X X & **Available & & \\
\hline Anaplectus sp. & X X X & Available & XXX & $†$ Available & X X X & Available & & \\
\hline Plectus sp. & X X X & Available & & Available & X X X & *Available & & **Available \\
\hline Pristionchus sp. & X X X & Available & X X X & Available & X X X & Available & & \\
\hline Ditylenchus dipsaci & X X X & Available & XXX & $†$ Available & X X X & Available & & \\
\hline Rhabditis sp. & X X X & Available & XXX & †Available & X X X & Available & & Available \\
\hline Steinernema carpocapsae & X X X & Available & XXX & $\dagger$ Available & X X X & *Available & XXX & Available \\
\hline Acrobeles sp. & X X & Available & & & X X & Available & & \\
\hline Acrobeloides sp. & X X X & Available & XXX & Available & XXX & Available & & \\
\hline Tylenchus sp. & X X X & Available & & & XXX & Available & & \\
\hline Laimaphelenchus penardi & XXX & Available & & & X X X & Available & & \\
\hline Aphelenchoides sp. & X X X & Available & & & X X X & Available & & \\
\hline Hemicycliophora sp. & X X X & Available & & & $\mathrm{X}$ & Available & & \\
\hline Criconema sp. & X X & Available & & & & Available & & \\
\hline Globodera rostochiensis & XXX & Available & XXX & $\uparrow$ Available & XXX & *Available & & \\
\hline Meloidogyne hapla & X X X & Available & XXX & Available & XXX & Available & XXX & Available \\
\hline
\end{tabular}

* The reference sequence obtained was for a different species of the same genus.

** The reference sequence was from this study.

$\dagger$ The reference sequence does not cover the full length of the marker.

dances. Finally, of the two taxa that were successfully assigned with the JB3-JB5GED marker, Steinernema was the taxon with the closest match between relative read frequencies and relative abundance. Reads of the genus Meloidogyne, the other identified taxon, deviated significantly from the relative abundance.

\section{Discussion}

Taxonomic coverage is crucial to any metabarcoding study. The ability of a marker to recover as many taxa as possible could easily be one of the main benchmarks for determining its suitability for metabarcoding. The main aim of this study was to evaluate the suitability of four widely used markers for metabarcoding of nematodes. Therefore, this discussion will focus on how the markers performed based on a consensus of all the assignment approaches rather than the differences in performance of the taxonomy assignment methods themselves. This subject is well covered in Holovachov et al. (2017) for aquatic nematodes. The results of the current study have shown that despite recommendations to adopt COI-based markers (Prosser et al. 2013, Peham et al. 2017), there is still a significant amount of effort needed to make this region a suitable barcode marker for nematodes. Besides being a region with currently poor taxonomic coverage, the lack of a comprehensive reference database strongly hampers its adoption for nematode metabarcoding in a manner similar to other animal groups such as birds, fish and insects. Although the length of the JB3-JB5GED gives it the appropriate size for application on a wide array of NGS platforms, it has the same limitation as other COI-based markers-their primer annealing sites are not sufficiently conserved across the diversity of groups such as nematodes (Deagle et al. 2014). Nonetheless, the fact that only two taxa could be assigned taxonomy based on the COI marker may not necessarily mean that these were the only taxa that were successfully recovered. The absence of sequences in the reference database that covered the location of this marker was also a reason for the failure of OTUs from some of the sampled taxa to be correctly assigned taxonomy. The use of highly degenerate primers has been shown to improve taxonomic coverage in some freshwater metazoans (Elbrecht and Leese 2017). It is not clear, however, how successful this may be for nematodes and how much of the resulting reads may cover taxa other than nematodes.

Another marker whose poor coverage could be attributed to insufficient matching reference sequences was the 18S rDNA-based SSUF04-SSUR22. Given that this region is well conserved and that there is a large collection of reference sequences, particularly for nematodes, the failure to detect eight members of the mock community was quite surprising. However, the issue with this marker appears to be its location within the full-length $18 \mathrm{~S}$ rDNA operon. As mentioned earlier, this marker is situated at the 
$5^{\prime}$ end of the 18S rDNA region and so unless the entire length of the 18S rDNA or this specific region are covered by a reference sequence, the reference is likely to not contain the homologous region for this maker. Although it has been used in a number of metagenetic studies involving meiofauna (Fonseca et al. 2010; Bik et al. 2012), its coverage within a diverse mock community has never been evaluated previously. Creer et al. (2010) examined the homology of their amplification primers to $\sim 170$ aligned sequences of nematodes and showed that $100 \%$ of base pair positions are conserved in the nematode sequences which supports this argument in suggesting that primer mismatch may not be the issue with this marker. Nonetheless, it is still popular for studies involving marine nematodes. For soil nematodes, however, there is still a number of taxa whose full SSU sequences need to be made available to make this marker broadly suitable.

The D2-D3 expansion segment of 28S rDNA region may be the region besides the $18 \mathrm{~S}$ rDNA region that has just the right amount of conservation and variability typical of a good metabarcoding marker. The region spanning these two high variability segments has also been the focus of phylogenetic studies for various groups of soil nematodes (Douda et al. 2013; Giblin-Davis et al. 2006; Kaplan et al. 2000; Litvaitis et al. 2000; Subbotin et al. 2011, 2008, $2007,2006,2005)$. It is also a common practice for phylogenetic analysis of certain groups of nematodes to be inferred based on both the commonly used 18S rDNA and the 28S rDNA region (Ahmed et al. 2013, Gutiérrez-Gutiérrez et al. 2013). Moreover, because the number of published studies on a particular genomic region may determine the number of reference sequences available publicly, it is quite convenient to build a reference database for a marker located within either the D2 or D3 segments. The entire length of the $28 \mathrm{~S}$ rDNA marker used for the mock community study is situated within the latter segment and so there was no issue of it falling out of place with most published sequences in NCBI nucleotide database. This therefore explains the high percentage assignments obtained for D3AfD3Br compared to the SSUF04-SSUR22 marker despite there being more $18 \mathrm{~S}$ rDNA than $28 \mathrm{~S}$ rDNA nematode sequences. A search using the keywords, 'Nematoda' and ' $18 \mathrm{~S}$ ' within the NCBI nucleotide database on $6^{\text {th }}$ February 2018 yielded 24,370 entries as compared to 19,674 for the keywords, 'Nematoda' and '28S'.

Unlike the SSUF04-SSUR22, the location of the NF1$18 \mathrm{Sr} 2 \mathrm{~b}$ marker within the $18 \mathrm{~S}$ rDNA region puts it within the flanks of most sequences used for reconstructing 18S rDNA-based phylum-wide phylogeny of nematodes (Holterman et al. 2006, van Megen et al. 2009). The utility of this marker benefits greatly from the ample reference sequences of $18 \mathrm{~S}$ rDNA and availability of highly conserved primer annealing sites. Although Porazinska et al. (2009) reported a very high coverage of this marker, there were still three taxa they could not account for in the sequence reads. According to the authors, this could have been caused by a number of factors: unmet species-specific PCR requirements, nematode-nematode template competition or nematode-non-nematode template competition.

There are several important community indices used in ecological studies that depend on absolute or relative abundance of taxa in the nematode community. These include the maturity index (Bongers 1990), enrichment, structure and basal indices (Ferris et al. 2001). Abundance has been used widely to compare processes such as community food web dynamics, stability and response to mineral and mechanical perturbations. In other words, almost all indices of community structure rely on abundance information of soil inhabiting taxa. Therefore, for metabarcoding to be accepted as an alternative to the more laborious, expensive and time-consuming classical morphology-based method of community analysis - for example - for soil health assessment or food web analysis, it is pertinent that the method is able to provide reliable abundance information based on the read frequencies of the recovered taxa. However, no mock community study to date has reported a strong correlation between actual abundance and read frequencies, implying that using read frequency data for computing any abundance-based index of a nematode community may produce inaccurate results. The same is true for this study; read number showed no correlation with actual abundance. In microbial ecology, however, read frequency information continues to be used even though the read frequency issue has been shown to transcend beyond studies involving metazoans such as nematodes to microbes, particularly in mixed species samples (Amend et al. 2010, Edgar 2017). This lack of association between relative abundance and read frequency therefore remains one of the key limitations of metabarcoding. The quantitative reproducibility of the replicates, however, was shown in this study. Thus, on both the lack of correlation between read frequencies and relative abundance and reproducibility across replicates, this study agrees with Porazinska et al. (2010b), especially for the NF1-18Sr2b marker results. The use of taxon-specific correction factors has been shown to improve the correlation between relative read frequency and proportion of a taxon's DNA in a sample (Krehenwinkel et al. 2017). Determination of such a correction factor requires knowledge of the PCR amplification bias for each taxon based on experimental data. Another attempt at improving abundance estimates was described for the 16S rDNA region with limited success by (Edgar 2017) . This approach requires prior knowledge of the number of copies of the marker within each taxon and the primer mismatch, which can be linked to amplification bias, within the primer annealing site. Both these approaches hold promise for abundance estimates and could benefit considerably from advancements in genome sequencing efforts. With knowledge of the genome, at least marker copy numbers and primer mismatch for most taxa can be determined. For nematodes, genome sequencing efforts such as those collated on the 959 Nematode Genomes webpage (http://www.nematodes.org/nematodegenomes) will provide pivotal information to improve abundance assessments from metabarcoding datasets. 
As observed from the different taxonomy assignment methods, methods usually employed in analysis pipelines such as QIIME (Caporaso et al. 2010), MOTHUR (Schloss et al. 2009) or USEARCH (Edgar 2010) can be used initially and complemented with BLAST or other methods especially for weak assignments. These methods depend on the use of curated reference databases like SILVA (Quast et al. 2013), UNITE (Kõljalg et al. 2013), RDP (Cole et al. 2014) or $\mathrm{PR}^{2}$ (Cole et al. 2014) which all get updated through publicly available sequences. For that reason, there are occasions when these databases are not up-to-date with the Nucleotide collection available via NCBI. Therefore, alternative methods such as BLAST search against the nucleotide collection may provide assignments that perhaps these pipeline-based methods might fail to provide. Despite the fact that a number of entries in GenBank may have dubious accuracies in terms of taxonomy (Mahé et al. 2012), most BLAST assignments in this study matched utax's assignments with sufficient support $(\geq 0.5)$.

\section{Conclusions}

In summary, for metabarcoding of nematodes, this study has demonstrated that there are many reasons to favor the NF1-18Sr2b marker as the most suitable both in terms of coverage and ease of access to reference sequences. The issue of non-specificity of this marker, whilst a problem, can mostly be avoided by extracting nematodes from soil before DNA extraction to make sure most non-targets are excluded. According to Creer et al. (2010), the fact that only a very minute proportion of soil or sediment volumes are made up of nematode biomass means that nematodes should always be extracted from the sediments first (Creer et al. 2010). Moreover, as stated by Peham et al. (2017), direct extraction kits can handle only a fraction of the recommended volumes of soil needed for analysis of nematode communities at the moment. In an ideal situation where a complete reference database of 28S rDNA is available, the D3Af-D3Br may be equally suitable alone or in combination with any of the $18 \mathrm{~S}$-based markers. In fact, claims have been made that suggest that the D2-D3 segment may provide a better barcoding marker than the 18S rDNA (Creer et al. 2010). For the COI region, unless the approach involves a cocktail of primers covering the diversity of the entire phylum as suggested by Prosser et al. (2013), the COI markers will continue to be of very little use in nematode metabarcoding. The 'primer cocktail' approach has not been tested on soil nematodes, and even if it worked, there is still the issue of very limited nematode reference sequences in public databases.

This study demonstrates how far a well curated nematode sequence database can go to facilitate the taxonomy assignment step of the analyses. A dedicated nematode database that is well curated by taxonomy experts will be helpful in eliminating the necessity for any further crosscheck of uclust or utax-based taxonomy assignments. As stated earlier, the main $\mathrm{rDNA}$ reference databases, $\mathrm{PR}^{2}$ and SILVA, have a number of entries with incomplete taxonomies and thus make it a necessity for the assignments be checked. This process can be time consuming especially if there is a large number of OTUs to be checked. This may require collaborative work between nematode taxonomists and molecular biologists.

Finally, when making recommendations for appraisal and adoption of new barcode marker(s) other than the ones known and used so far, an important consideration that always has to be made is the availability of a comprehensive reference database. It will take a tremendous amount of work to develop new reference databases as comprehensive as that which exists now for the $18 \mathrm{~S}$ or $28 \mathrm{~S}$ rDNA region.

\section{Acknowledgements}

The authors wish to thank the European Phytosanitary Research Coordination (EUPHRESCO) for funding this research. We would also like to thank Erin Lewis and Ummey Hany for helping with the sequencing and Rachel Glover for providing advice on the bioinformatics.

\section{References}

Ahmed M, van de Vossenberg BTLH, Cornelisse C, Karssen G (2013) On the species status of the root-knot nematode Meloidogyne ulmi Palmisano \& Ambrogioni, 2000 (Nematoda, Meloidogynidae). ZooKeys, 1-27. https://doi.org/10.3897/zookeys.362.6352

Amend AS, Seifert KA, Bruns TD (2010) Quantifying microbial communities with 454 pyrosequencing: does read abundance count? Molecular ecology 19: 5555-5565. https://doi.org/10.1111/j.1365294X.2010.04898.x

Anderson TJC, Blouin MS, Beech RN (1998) Population biology of parasitic nematodes: applications of genetic markers. Advances in parasitology 41: 219-283. https://doi.org/10.1016/S0065-308X(08)60425-X

Benson DA, Cavanaugh M, Clark K, Karsch-Mizrachi I, Ostell J, Pruitt KD, Sayers EW (2018) GenBank. Nucleic acids research 46: D41D47. https://doi.org/10.1093/nar/gkx1094

Bik HM, Sung WAY, De Ley P, Baldwin JG, Sharma J, Rocha-Olivares A, Thomas WK (2012) Metagenetic community analysis of microbial eukaryotes illuminates biogeographic patterns in deep-sea and shallow water sediments. Molecular Ecology 21: 1048-1059. https://doi.org/10.1111/j.1365-294X.2011.05297.x

Blaxter ML, De Ley P, Garey JR, Liu LX (1998) A molecular evolutionary framework for the phylum Nematoda. Nature 392: 71-75. https://doi.org/10.1038/32160

Blouin MS, Yowell CA, Courtney CH, Dame JB (1995) Host movement and the genetic structure of populations of parasitic nematodes. Genetics 141: 1007-1014.

Blouin MS, Yowell CA, Courtney CH, Dame JB (1998) Substitution bias, rapid saturation, and the use of mtDNA for nematode systematics. Molecular biology and evolution 15: 1719-1727. https://doi. org/10.1093/oxfordjournals.molbev.a025898

Bongers T (1990) The maturity index: an ecological measure of environmental disturbance based on nematode species composition. Oecologia 83: 14-19. https://doi.org/10.1007/BF00324627 
Bowles J, Blair D, McManus DP (1992) Genetic variants within the genus Echinococcus identified by mitochondrial DNA sequencing. Molecular and biochemical parasitology 54: 165-173. https://doi. org/10.1016/0166-6851(92)90109-W

Camacho C, Coulouris G, Avagyan V, Ma N, Papadopoulos J, Bealer K, Madden TL (2009) BLAST+: architecture and applications. BMC bioinformatics 10: 421. https://doi.org/10.1186/1471-2105-10-421

Caporaso JG, Kuczynski J, Stombaugh J, Bittinger K, Bushman FD, Costello EK, Fierer N, Peña AG, Goodrich JK, Gordon JI, Huttley GA, Kelley ST, Knights D, Koenig JE, Ley RE, Lozupone CA, McDonald D, Muegge BD, Pirrung M, Reeder J, Sevinsky JR, Turnbaugh PJ, Walters WA, Widmann J, Yatsunenko T, Zaneveld J, Knight R (2010) QIIME allows analysis of high-throughput community sequencing data. Nature methods 7: 335-336. https://doi. org/10.1038/nmeth.f.303

Cole JR, Wang Q, Fish JA, Chai B, McGarrell DM, Sun Y, Brown CT, Porras-Alfaro A, Kuske CR, Tiedje JM (2014) Ribosomal Database Project: Data and tools for high throughput rRNA analysis. Nucleic Acids Research 42: D633-D642. https://doi.org/10.1093/nar/gkt1244

Creer S, Fonseca VG, Porazinska DL, Giblin-Davis RM, Sung W, Power DM, Packer M, Carvalho GR, Blaxter ML, Lambshead PJD, Thomas WK (2010) Ultrasequencing of the meiofaunal biosphere: Practice, pitfalls and promises. Molecular Ecology 19: 4-20. https:// doi.org/10.1111/j.1365-294X.2009.04473.x

Deagle BE, Jarman SN, Coissac E, Pompanon F, Taberlet P (2014) DNA metabarcoding and the cytochrome c oxidase subunit I marker: not a perfect match. Biology letters 10: 20140562. https://doi. org/10.1098/rsbl.2014.0562

Derycke S, Vanaverbeke J, Rigaux A, Backeljau T, Moens T (2010) Exploring the use of cytochrome oxidase c subunit 1 (COI) for DNA barcoding of free-living marine nematodes. PLoS One 5: e13716. https://doi.org/10.1371/journal.pone.0013716

Douda O, Marek M, Zouhar M, Ryšánek P (2013) Insights into the structure and phylogeny of the 28S rRNA expansion segments D2 and D3 of the plant-infecting nematodes from the genus Ditylenchus (Nematoda: Anguinidae). Phytopathologia Mediterranea: 84-97.

Edgar RC (2004) MUSCLE: multiple sequence alignment with high accuracy and high throughput. Nucleic Acids Res 32: 1792-1797. https://doi.org/10.1093/nar/gkh340

Edgar RC (2010) Search and clustering orders of magnitude faster than BLAST. Bioinformatics 26: 2460-2461. https://doi.org/10.1093/ bioinformatics/btq461

Edgar RC (2013) UPARSE: highly accurate OTU sequences from microbial amplicon reads. Nature Methods 10: 996-8. https://doi. org/10.1038/nmeth.2604

Edgar RC (2017) UNBIAS: An attempt to correct abundance bias in $16 \mathrm{~S}$ sequencing, with limited success. bioRxiv: 124149. https://doi. org/10.1101/124149

Edgar RC, Flyvbjerg H (2015) Error filtering, pair assembly and error correction for next-generation sequencing reads. Bioinformatics 31: 3476-3482. https://doi.org/10.1093/bioinformatics/btv401

Elbrecht V, Leese F (2017) Validation and Development of COI Metabarcoding Primers for Freshwater Macroinvertebrate Bioassessment . Frontiers in Environmental Science 5: 11. https://doi. org/10.3389/fenvs. 2017.00038

Elder J, Turner B (1995) 70 The Quarterly review of biology Elder Jr JF, Turner BJ. Concerted evolution of repetitive DNA sequences in eukaryotes. Q Rev Biol 70: 297-320. https://doi.org/10.1086/419073
Ellis RE, Sulston JE, Coulson AR (1986) The rDNA of C. elegans: sequence and structure. Nucleic acids research 14: 2345-2364. https:// doi.org/10.1093/nar/14.5.2345

Ferris H, Bongers T, De Goede RGM (2001) A framework for soil food web diagnostics: extension of the nematode faunal analysis concept. Applied Soil Ecology 18: 13-29. https://doi.org/10.1016/S09291393(01)00152-4

Floyd R, Abebe E, Papert A, Blaxter M (2002) Molecular barcodes for soil nematode identification. Molecular Ecology 11: 839-850. https://doi.org/10.1046/j.1365-294X.2002.01485.x

Folmer O, Black M, Hoeh W, Lutz R, Vrijenhoek R (1994) DNA primers for amplification of mitochondrial cytochrome c oxidase subunit I from diverse metazoan invertebrates. Molecular Marine Biology and Biotechnology 3: 294-299. https://doi.org/10.1371/journal.pone.0013102

Fonseca VG, Carvalho GR, Nichols B, Quince C, Johnson HF, Neill SP, Lambshead JD, Thomas WK, Power DM, Creer S (2014) Metagenetic analysis of patterns of distribution and diversity of marine meiobenthic eukaryotes. Global Ecology and Biogeography 23: 1293-1302. https://doi.org/10.1111/geb.12223

Fonseca VG, Carvalho GR, Sung W, Johnson HF, Power DM, Neill SP, Packer M, Blaxter ML, Lambshead PJD, Thomas WK, Creer S (2010) Second-generation environmental sequencing unmasks marine metazoan biodiversity. Nature communications 1: 1-8. https:// doi.org/10.1038/ncomms1095

Giblin-Davis RM, Ye W, Kanzaki N, Williams D, Morris K, Thomas WK (2006) Stomatal ultrastructure, molecular phylogeny, and description of Parasitodiplogaster laevigata n. sp.(Nematoda: Diplogastridae), a parasite of fig wasps. Journal of nematology 38 : 137-149.

Guillou L, Bachar D, Audic S, Bass D, Berney C, Bittner L, Boutte C, Burgaud G, De Vargas C, Decelle J, Del Campo J, Dolan JR, Dunthorn M, Edvardsen B, Holzmann M, Kooistra WHCF, Lara E, Le Bescot N, Logares R, Mahé F, Massana R, Montresor M, Morard R, Not F, Pawlowski J, Probert I, Sauvadet AL, Siano R, Stoeck T, Vaulot D, Zimmermann P, Christen R (2012) The Protist Ribosomal Reference database $\left(\mathrm{PR}^{2}\right)$ : a catalog of unicellular eukaryote small sub-unit rRNA sequences with curated taxonomy. Nucleic acids research 41: D597-D604. https://doi.org/10.1093/nar/gks1160

Gutiérrez-Gutiérrez C, Cantalapiedra-Navarrete C, Montes-Borrego M, Palomares-Rius JE, Castillo P (2013) Molecular phylogeny of the nematode genus Longidorus (Nematoda: Longidoridae) with description of three new species. Zoological Journal of the Linnean Society 167: 473-500. https://doi.org/10.1111/zoj.12019

Hajibabaei M, Singer GAC, Hebert PDN, Hickey DA (2007) DNA barcoding: how it complements taxonomy, molecular phylogenetics and population genetics. Trends in Genetics 23: 167-172. https:// doi.org/10.1016/j.tig.2007.02.001

Hall TA (1999) BioEdit: a user-friendly biological sequence alignment editor and analysis program for Windows 95/98/NT. Nucleic Acids Symposium series 41: 95-98.

Hebert PDN, Cywinska A, Ball SL, DeWaard JR (2003) Biological identifications through DNA barcodes. Proc Roy Soc Lond B Biol Sci 270: 313-321. https://doi.org/10.1098/rspb.2002.2218

Hebert PDN, Stoeckle MY, Zemlak TS, Francis CM (2004) Identification of birds through DNA barcodes. PLoS Biology 2: e312. https:// doi.org/10.1371/journal.pbio.0020312

Hebert PDN, Ratnasingham S, Zakharov EV, Telfer AC, LevesqueBeaudin V, Milton MA, Pedersen S, Jannetta P (2016) Counting an- 
imal species with DNA barcodes: Canadian insects. Phil. Trans. R. Soc. B 371: 20150333. https://doi.org/10.1098/rstb.2015.0333

Hillis DM, Dixon MT (1991) Ribosomal DNA: molecular evolution and phylogenetic inference. The Quarterly review of biology 66: 411-453. https://doi.org/10.1086/417338

Holovachov O, Haenel Q, Bourlat SJ, Jondelius U (2017) Taxonomy assignment approach determines the efficiency of identification of OTUs in marine nematodes. Royal Society open science 4: 170315. https://doi.org/10.1098/rsos.170315

Holterman M, van der Wurff A, van den Elsen S, van Megen H, Bongers T, Holovachov O, Bakker J, Helder J (2006) Phylum-wide analysis of SSU rDNA reveals deep phylogenetic relationships among nematodes and accelerated evolution toward crown clades. Molecular biology and evolution 23: 1792-1800. https://doi.org/10.1093/molbev/ms1044

Janssen T, Karssen G, Verhaeven M, Coyne D, Bert W (2016) Mitochondrial coding genome analysis of tropical root-knot nematodes (Meloidogyne) supports haplotype based diagnostics and reveals evidence of recent reticulate evolution. Scientific reports 6: 1-13. https://doi.org/10.1038/srep22591

Kaplan DT, Thomas WK, Frisse LM, Sarah JL, Stanton JM, Speijer PR, Marin DH, Opperman CH (2000) Phylogenetic analysis of geographically diverse Radopholus similis via rDNA sequence reveals a monomorphic motif. Journal of Nematology 32: 134-142.

Kõljalg U, Nilsson RH, Abarenkov K, Tedersoo L, Taylor AFS, Bahram M, Bates ST, Bruns TD, Bengtsson-Palme J, Callaghan TM, Douglas B, Drenkhan T, Eberhardt U, Dueñas M, Grebenc T, Griffith GW, Hartmann M, Kirk PM, Kohout P, Larsson E, Lindahl BD, Lücking R, Martín MP, Matheny PB, Nguyen NH, Niskanen T, Oja J, Peay KG, Peintner U, Peterson M, Põldmaa K, Saag L, Saar I, Schüßler A, Scott JA, Senés C, Smith ME, Suija A, Taylor DL, Telleria MT, Weiss M, Larsson K-H (2013) Towards a unified paradigm for sequence-based identification of fungi. Molecular Ecology 22: 5271-5277. https://doi.org/10.1111/mec.12481

Krehenwinkel H, Wolf M, Lim JY, Rominger AJ, Simison WB, Gillespie RG (2017) Estimating and mitigating amplification bias in qualitative and quantitative arthropod metabarcoding. Scientific reports 7: 1-12. https://doi.org/10.1038/s41598-017-17333-x

Kumar S, Stecher G, Tamura K (2016) MEGA7: molecular evolutionary genetics analysis version 7.0 for bigger datasets. Molecular biology and evolution 33: 1870-1874. https:/doi.org/10.1093/molbev/msw054

Letunic I, Bork P (2016) Interactive tree of life (iTOL) v3: an online tool for the display and annotation of phylogenetic and other trees. Nucleic acids research 44: W242-W245. https://doi.org/10.1093/nar/gkw290

De Ley P, Blaxter ML (2002) Systematic position and phylogeny. In: Lee DL (Ed.) The biology of nematodes. Taylor \& Francis London, London, UK, 1-30. https://doi.org/10.1201/b12614-2

Litvaitis MK, Bates JW, Hope WD, Moens T (2000) Inferring a classification of the Adenophorea (Nematoda) from nucleotide sequences of the D3 expansion segment (26/28S rDNA). Canadian Journal of Zoology 78: 911-922. https://doi.org/10.1139/z00-039

Mahé S, Duhamel M, Le Calvez T, Guillot L, Sarbu L, Bretaudeau A, Collin O, Dufresne A, Kiers ET, Vandenkoornhuyse P (2012) PHYMYCO-DB: a curated database for analyses of fungal diversity and evolution. PloS one 7: e43117-e43117. https://doi.org/10.1371/journal.pone. 0043117

van Megen H, van den Elsen S, Holterman M, Karssen G, Mooyman P, Bongers T, Holovachov O, Bakker J, Helder J (2009) A phylogenetic tree of nematodes based on about 1200 full-length small subunit ribosomal DNA sequences. Nematology 11: 927-950. https://doi. org/10.1163/156854109X456862

Miller MA, Pfeiffer W, Schwartz T (2010) Creating the CIPRES Science Gateway for inference of large phylogenetic trees. In: Gateway Computing Environments Workshop (GCE), 2010. Ieee, 1-8. https://doi.org/10.1109/GCE.2010.5676129

Munch K, Boomsma W, Huelsenbeck JP, Willerslev E, Nielsen R (2008) Statistical assignment of DNA sequences using Bayesian phylogenetics. Systematic biology 57: 750-757. https://doi. org/10.1080/10635150802422316

NCBI Resource Coordinators (2016) Database resources of the national center for biotechnology information. Nucleic acids research 44 : D7-D19. https://doi.org/10.1093/nar/gkv1290

Nunn GB (1992) Nematode molecular evolution: an investigation of evolutionary patterns among nematodes based upon DNA sequences. University of Nottingham, UK.

Peham T, Steiner FM, Schlick-Steiner BC, Arthofer W (2017) Are we ready to detect nematode diversity by next generation sequencing? Ecology and Evolution 7: 4147-4151. https://doi.org/10.1002/ ece3.2998

Porazinska DL, Giblin-Davis RM, Faller L, Farmerie W, Kanzaki N, Morris K, Powers TO, Tucker AE, Sung W, Thomas WK (2009) Evaluating high-throughput sequencing as a method for metagenomic analysis of nematode diversity. Molecular Ecology Resources 9: 1439-1450. https://doi.org/10.1111/j.1755-0998.2009.02611.x

Porazinska DL, Sung WAY, Giblin-Davis RM, Thomas WK (2010a) Reproducibility of read numbers in high-throughput sequencing analysis of nematode community composition and structure. Molecular Ecology Resources 10: 666-676. https://doi.org/10.1111/ j.1755-0998.2009.02819.x

Porazinska DL, Giblin-Davis RM, Powers TO, Thomas WK (2012) Nematode spatial and ecological patterns from tropical and temperate rainforests. PLoS One 7: e44641. https://doi.org/10.1371/journal.pone. 0044641

Porazinska DL, Giblin-Davis RM, Esquivel A, Powers TO, Sung WAY, Thomas WK (2010b) Ecometagenetics confirm high tropical rainforest nematode diversity. Molecular Ecology 19: 5521-5530. https://doi.org/10.1111/j.1365-294X.2010.04891.X

Prosser SWJ, Velarde-Aguilar MG, León-Règagnon V, Hebert PDN (2013) Advancing nematode barcoding: a primer cocktail for the cytochrome c oxidase subunit I gene from vertebrate parasitic nematodes. Molecular Ecology Resources 13: 1108-1115. https://doi. org/10.1111/1755-0998.12082

Quast C, Pruesse E, Yilmaz P, Gerken J, Schweer T, Yarza P, Peplies J, Glöckner FO (2013) The SILVA ribosomal RNA gene database project: Improved data processing and web-based tools. Nucleic Acids Research 41: D590-D596. https://doi.org/10.1093/nar/gks1219

Ramage T, Martins-Simoes P, Mialdea G, Allemand R, Duplouy A, Rousse P, Davies N, Roderick GK, Charlat S (2017) A DNA barcode-based survey of terrestrial arthropods in the Society Islands of French Polynesia: host diversity within the SymbioCode Project. European Journal of Taxonomy: 1-13. https://doi.org/10.5852/ejt.2017.272

Ratnasingham S, Hebert PDN (2007) BOLD: The Barcode of Life Data System (http://www.barcodinglife.org). Molecular Ecology Resources 7: 355-364. https://doi.org/10.1111/j.1471-8286.2007.01678.x

Sapkota R, Nicolaisen M (2015) High-throughput sequencing of nematode communities from total soil DNA extractions. BMC Ecology 15: 1-8. https://doi.org/10.1186/s12898-014-0034-4 
Sayers EW, Agarwala R, Bolton EE, Brister JR, Canese K, Clark K, Connor R, Fiorini N, Funk K, Hefferon T, Holmes JB, Kim S, Kimchi A, Kitts PA, Lathrop S, Lu Z, Madden TL, Marchler-Bauer A, Phan L, Schneider VA, Schoch CL, Pruitt KD, Ostell J (2018) Database resources of the National Center for Biotechnology Information. Nucleic Acids Research 47: D23-D28. https://doi.org/10.1093/nar/gky1069 Schloss PD, Westcott SL, Ryabin T, Hall JR, Hartmann M, Hollister EB, Lesniewski RA, Oakley BB, Parks DH, Robinson CJ, Sahl JW, Stres B, Thallinger GG, Van Horn DJ, Weber CF (2009) Introducing mothur: Open-source, platform-independent, community-supported software for describing and comparing microbial communities. Applied and Environmental Microbiology 75: 7537-7541. https://doi. org/10.1128/AEM.01541-09

Seinhorst JW (1955) Een eenvoudige methode voor het afscheiden van aaltjes uit grond. European Journal of Plant Pathology 61: 188-190.

Siddiqi MR (2000) Tylenchida: parasites of plants and insects. CABI Publishing, Wallingford, UK, Wallingford, 1-833. https://doi. org/10.1007/BF02651811

Stamatakis A (2014) RAxML version 8: a tool for phylogenetic analysis and post-analysis of large phylogenies. Bioinformatics 30: 13121313. https://doi.org/10.1093/bioinformatics/btu033

Subbotin SA, Sturhan D, Chizhov VN, Vovlas N, Baldwin JG (2006) Phylogenetic analysis of Tylenchida Thorne, 1949 as inferred from D2 and D3 expansion fragments of the 28S rRNA gene sequences. Nematology 8: 455-474. https://doi.org/10.1163/156854106778493420

Subbotin SA, Ragsdale EJ, Mullens T, Roberts PA, Mundo-Ocampo M, Baldwin JG (2008) A phylogenetic framework for root lesion nematodes of the genus Pratylenchus (Nematoda): Evidence from 18S and D2-D3 expansion segments of 28S ribosomal RNA genes and morphological characters. Molecular Phylogenetics and Evolution 48: 491-505. https://doi.org/10.1016/j.ympev.2008.04.028

Subbotin SA, Vovlas N, Crozzoli R, Sturhan D, Lamberti F, Moens M, Baldwin JG (2005) Phylogeny of Criconematina Siddiqi, 1980 (Nematoda: Tylenchida) based on morphology and D2-D3 expansion segments of the 28S-rRNA gene sequences with application of a secondary structure model. Nematology 7: 927-944. https://doi. org/10.1163/156854105776186307

Subbotin SA, Sturhan D, Vovlas N, Castillo P, Tambe JT, Moens M, Baldwin JG (2007) Application of the secondary structure model of rRNA for phylogeny: D2-D3 expansion segments of the LSU gene of plant-parasitic nematodes from the family Hoplolaimidae Filipjev, 1934. Molecular Phylogenetics and Evolution 43: 881-890. https://doi.org/10.1016/j.ympev.2006.09.019

Subbotin SA, Inserra RN, Marais M, Mullin P, Powers TO, Roberts PA, Van Den Berg E, Yeates GW, Baldwin JG (2011) Diversity and phylogenetic relationships within the spiral nematodes of Helicotylenchus Steiner, 1945 (Tylenchida: Hoplolaimidae) as inferred from analysis of the D2-D3 expansion segments of 28S rRNA gene sequences. Nematology 13: 333-345. https://doi.org/10.1163/138855410X520936

Whitehead AG, Hemming JR (1965) A comparison of some quantitative methods of extracting small vermiform nematodes from soil. Annals of applied Biology 55: 25-38. https://doi. org/10.1111/j.1744-7348.1965.tb07864.x
Wilkinson MJ, Szabo C, Ford CS, Yarom Y, Croxford AE, Camp A, Gooding P (2017) Replacing Sanger with Next Generation Sequencing to improve coverage and quality of reference DNA barcodes for plants. Scientific Reports 7: 1-11. https://doi.org/10.1038/ srep46040

Yarza P, Richter M, Peplies J, Euzeby J, Amann R, Schleifer K-H, Ludwig W, Glöckner FO, Rosselló-Móra R (2008) The All-Species Living Tree project: a 16S rRNA-based phylogenetic tree of all sequenced type strains. Systematic and applied microbiology 31 : 241-250. https://doi.org/10.1016/j.syapm.2008.07.001

Zhang Z, Schwartz S, Wagner L, Miller W (2000) A greedy algorithm for aligning DNA sequences. Journal of Computational biology 7: 203-214. https://doi.org/10.1089/10665270050081478

\section{Data accessibility}

Mock community sequence data for the different markers canberetrievedunderstudy accessionnumberPRJEB27581 (sample accession numbers ERS2593880-ERS2593883 for NF1-18Sr2b marker, ERS2593884-ERS2593887 for SSUF04-SSUR22 marker, ERS2593888-ERS2593891 for D3Af-D3Br marker and ERS2593892-ERS2593895 for JB3-JB5GED marker).

\section{Supplementary material 1 \\ Tables S1-S6}

Authors: Mohammed Ahmed, Matthew Alan Back, Thomas Prior, Gerrit Karssen, Rebecca Lawson, Ian Adams, Melanie Sapp Data type: species data

Copyright notice: This dataset is made available under the Open Database License (http://opendatacommons.org/licenses/odbl/1.0/). The Open Database License (ODbL) is a license agreement intended to allow users to freely share, modify, and use this Dataset while maintaining this same freedom for others, provided that the original source and author(s) are credited. Link: https://doi.org/10.3897/mbmg.2.36408.suppl1

\section{Supplementary material 2 Custom python script}

Authors: Mohammed Ahmed, Matthew Alan Back, Thomas Prior, Gerrit Karssen, Rebecca Lawson, Ian Adams, Melanie Sapp Data type: source code

Copyright notice: This dataset is made available under the Open Database License (http://opendatacommons.org/licenses/odbl/1.0/). The Open Database License (ODbL) is a license agreement intended to allow users to freely share, modify, and use this Dataset while maintaining this same freedom for others, provided that the original source and author(s) are credited. Link: https://doi.org/10.3897/mbmg.2.36408.suppl2 